\title{
Atmospheric influences on infrared-laser signals used for occultation measurements between Low Earth Orbit satellites
}

\author{
S. Schweitzer, G. Kirchengast, and V. Proschek \\ Wegener Center for Climate and Global Change (WEGC) and Institute for Geophysics, Astrophysics and \\ Meteorology/Institute of Physics (IGAM/IP), University of Graz, Graz, Austria
}

Received: 27 March 2011 - Published in Atmos. Meas. Tech. Discuss.: 10 May 2011

Revised: 29 August 2011 - Accepted: 14 September 2011 - Published: 21 October 2011

\begin{abstract}
LEO-LEO infrared-laser occultation (LIO) is a new occultation technique between Low Earth Orbit (LEO) satellites, which applies signals in the short wave infrared spectral range (SWIR) within $2 \mu \mathrm{m}$ to $2.5 \mu \mathrm{m}$. It is part of the LEO-LEO microwave and infrared-laser occultation (LMIO) method that enables to retrieve thermodynamic profiles (pressure, temperature, humidity) and altitude levels from microwave signals and profiles of greenhouse gases and further variables such as line-of-sight wind speed from simultaneously measured LIO signals. Due to the novelty of the LMIO method, detailed knowledge of atmospheric influences on LIO signals and of their suitability for accurate trace species retrieval did not yet exist. Here we discuss these influences, assessing effects from refraction, trace species absorption, aerosol extinction and Rayleigh scattering in detail, and addressing clouds, turbulence, wind, scattered solar radiation and terrestrial thermal radiation as well. We show that the influence of refractive defocusing, foreign species absorption, aerosols and turbulence is observable, but can be rendered small to negligible by use of the differential transmission principle with a close frequency spacing of LIO absorption and reference signals within $0.5 \%$. The influences of Rayleigh scattering and terrestrial thermal radiation are found negligible. Cloud-scattered solar radiation can be observable under bright-day conditions, but this influence can be made negligible by a close time spacing (within $5 \mathrm{~ms}$ ) of interleaved laser-pulse and background signals. Cloud extinction loss generally blocks SWIR signals, except very thin or sub-visible cirrus clouds, which can be addressed by retrieving a cloud layering profile and exploiting it in the trace species retrieval. Wind can have a small influence on the trace species absorption, which can be made negligible by using a simultaneously retrieved or a moderately accurate
\end{abstract}

Correspondence to: S. Schweitzer (susanne.schweitzer@uni-graz.at) background wind speed profile. We conclude that the set of SWIR channels proposed for implementing the LMIO method (Kirchengast and Schweitzer, 2011) provides adequate sensitivity to accurately retrieve eight trace species of key importance to climate and atmospheric chemistry $\left(\mathrm{H}_{2} \mathrm{O}\right.$, $\mathrm{CO}_{2},{ }^{13} \mathrm{CO}_{2}, \mathrm{C}^{18} \mathrm{OO}, \mathrm{CH}_{4}, \mathrm{~N}_{2} \mathrm{O}, \mathrm{O}_{3}, \mathrm{CO}$ ) in the upper troposphere/lower stratosphere region outside clouds under all atmospheric conditions. Two further species $\left(\mathrm{HDO}, \mathrm{H}_{2}^{18} \mathrm{O}\right)$ can be retrieved in the upper troposphere.

\section{Introduction}

Recently, the satellite mission ACCURATE - climate benchmark profiling of greenhouse gases and thermodynamic variables and wind from space - was proposed to the European Space Agency by Kirchengast et al. (2010) and received positive evaluation and recommendations for further study. This mission concept applies the occultation measurement principle (Phinney and Anderson, 1968; Kirchengast, 2004) in a novel way, called LEO-LEO microwave and infrared-laser occultation (LMIO), recently introduced by Kirchengast and Schweitzer (2011). A graphical view of the concept is given in Fig. 1. Laser signals in the short wave infrared (SWIR) spectral region (within $2 \mu \mathrm{m}$ to $2.5 \mu \mathrm{m}$; pulsed signals) are used simultaneously with microwave (MW) signals at cmand mm-wavelengths (within $8 \mathrm{GHz}$ to $30 \mathrm{GHz}$ and $175 \mathrm{GHz}$ to $200 \mathrm{GHz}$; continuous-wave signals). These signals are transmitted between two Low Earth Orbit (LEO) satellites and thereby pass the Earth's atmosphere; the focus region is the upper troposphere/lower stratosphere (UTLS) $(5 \mathrm{~km}$ to $35 \mathrm{~km})$.

The signals are refracted and absorbed during propagation which enables to retrieve vertical profiles of thermodynamic and dynamic variables (refractivity, pressure, temperature, specific humidity, line-of-sight wind speed) and composition variables (greenhouse gas/isotope concentrations of

Published by Copernicus Publications on behalf of the European Geosciences Union. 


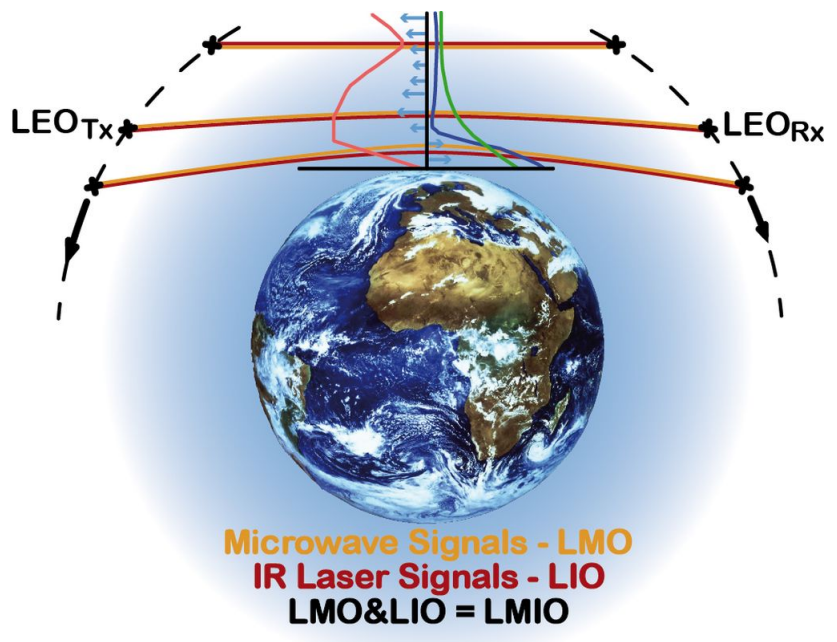

Fig. 1. Overview of the measurement concept of the ACCURATE satellite mission applying the LMIO method.

$\mathrm{H}_{2} \mathrm{O}, \mathrm{CO}_{2},{ }^{13} \mathrm{CO}_{2}, \mathrm{C}^{18} \mathrm{OO}, \mathrm{CH}_{4}, \mathrm{~N}_{2} \mathrm{O}, \mathrm{O}_{3}, \mathrm{CO}, \mathrm{HDO}$, $\mathrm{H}_{2}{ }^{18} \mathrm{O}$ ) in the free atmosphere. By-products can be profiles of cloud liquid water (from the MW signals), cloud layering and aerosol extinction coefficient (from the SWIR signals) as well as turbulence strength (from both). The retrieved profiles are expected very accurate, have a high vertical resolution (about $1 \mathrm{~km}$ ) and typically cover the whole UTLS region, which is an important region for climate and chemistry (Li et al., 2008; Steiner et al., 2009). For a detailed introduction of the LMIO method, and the proposed mission concept ACCURATE to implement it, see Kirchengast and Schweitzer (2011); Kirchengast et al. (2010); Schweitzer (2010).

The part using the SWIR signals is called LEO-LEO infrared-laser occultation (LIO) and is suitable for retrieving profiles of trace species and line-of-sight (l.o.s.) wind speed (besides the byproducts mentioned above; details on the trace species retrieval are given by Proschek et al., 2011a). The retrieval principle is based on differential transmission (Kursinski et al., 2002; Gorbunov and Kirchengast, 2007), alternatively also called differential absorption principle. Regarding trace species, this means that each species is derived from the ratio of the transmissions of two signals (which corresponds to a difference in the $\mathrm{dB}$ space of log-transmission, proportional to optical thickness), termed a channel pair. One of these signals is primarily absorbed by the target species of interest and is called absorption (on-line) signal. The other signal is ideally not absorbed at all and only affected by broadband background effects; it is called reference (off-line) signal.

Exploiting these characteristics of the two signals, most background effects can be eliminated by using differential transmission profiles. This together with a high signalto-noise ratio and a self-calibration step in the retrieval algorithm, which is intrinsic to the occultation method since the transmitted intensities during an occultation event are generally normalised with the unattenuated intensity measured at the top of the atmosphere, is the reason why the LIO retrieval results are expected to be very accurate and essentially free of measurement biases (Kirchengast and Schweitzer, 2007, 2011; Schweitzer, 2010; Proschek et al., 2011a). This means that the retrieval results are of high quality on a single-occultation-event basis, and therefore effectively independent of the specific LMIO mission that provides the measurements. It enables direct comparability of data from, e.g. a series of successive missions, also without overlap. This long-term stability property of the data is very important in climate research.

The part using the MW signals is called LEO-LEO microwave occultation (LMO), which is well established already, even though it was not yet operated in space. More details on this technique, its capabilities and the quality of retrieval results can be found in Feng et al. (2000); Herman et al. (2004); Kursinski et al. (2002, 2004); Kirchengast and Høeg (2004); Gorbunov and Kirchengast (2005, 2007); Kursinski et al. (2009); Schweitzer et al. (2011). A closely related occultation method is the GNSS-LEO radio occultation (GRO), which uses L-band signals from the US Global Positioning System (GPS) system. GRO is meanwhile regularly operated in space and proved to be very useful for atmosphere and climate research and weather forecasting (e.g. Kursinski et al., 1997; Steiner et al., 2001, 2009; Hajj et al., 2002; Gobiet et al., 2005; Healy and Thépaut, 2006; Anthes et al., 2008; Ho et al., 2009; Cardinali, 2009).

The LIO technique is the novel part of the LMIO method and was an original conception for the ACCURATE mission, adding to the LMO technique of the predecessor mission concept ACE+ (Kirchengast and Høeg, 2004). Hence, all scientific and technical characteristics of this technique needed to be assessed essentially from the very beginning. One important point for this assessment was the development of tools to simulate the measurements and to retrieve the atmospheric variables. For the simulation of the measurements, it was necessary to identify atmospheric and instrumental influences on the propagation of the signals. In this paper, we focus on investigation of the atmospheric influences which are of importance for the LIO technique and the utility of the LIO signals for accurate trace species retrieval (details in Sect. 2.1). We also show the total impact of these atmospheric influences on the received signal intensity; this total influence is an important ingredient for power-budget calculations along the LEO-LEO intersatellite link and is needed to determine power requirements in an LIO mission design. Likewise it is an important input to generate simulated measurements subsequently used in retrieval processing in the frame of end-to-end simulations (Proschek et al., 2011a).

As implemented by ACCURATE, LIO is nominally operated in combination with LMO, i.e. as a full LMIO approach. From the measurement of phase and amplitude of 
LMO signals, complemented by precise position and velocity data of the LEO satellites, profiles of the thermodynamic variables pressure, temperature and humidity can be derived as well as accurate altitude levels. Hence, just the intensity of the SWIR signals needs to be evaluated additionally to be able to derive the atmospheric trace species and the l.o.s. wind speed from LIO measurements (Proschek et al., 2011a). In principle, LIO could also be used standalone if sophisticated instruments measuring also the phase of these infrared signals are available (allowing retrieval of altitude, pressure, and temperature). But this would require robustly tracked continuous-wave signals, which need much more power and have more limitation in intermittent cloudiness than incoherent detection of the intensity of pulsed signals without active tracking. Since the combined method allows use of such simple pulsed signals, the combined LMIO mode is preferable. Another option would be to take pressure, temperature and altitude information, which are needed in the LIO retrieval process, from high-quality atmospheric fields (e.g. ECMWF analyses or short-term forecasts), but this compromises the independent benchmarking capability of the full LMIO method. Any of these implementations of LIO needs a careful characterisation and understanding of atmospheric influences on the propagating SWIR signals, which is therefore the focus of this study.

The paper is structured as follows. We first present the method used to investigate the atmospheric influences on LIO (Sect. 2). Next we discuss each influence individually in Sect. 3, whereby the refractive effects are presented first (Sects. 3.1 and 3.2), followed by the influences directly affecting the transmission and differential transmission of the signals (Sects. 3.3 to 3.7). The influences discussed but not analysed in detail within this study are addressed in Sect. 3.8. Finally, results are summarised and conclusions drawn in Sect. 4.

\section{Method}

The influence of atmospheric processes on the transmission of LIO signals was studied by means of propagation simulations with the End-to-end Generic Occultation Performance Simulation and Processing System (EGOPS) and eXtended EGOPS (xEGOPS) (Fritzer et al., 2010a,b). This system provides the framework for end-to-end simulations as well as processing of real data of occultation missions, the latter for GRO only. It was originally developed for studying and evaluating GRO and LMO satellite missions and more recently extended by capabilities needed for characterising the LIO method. Below, we describe the analysis layout used for this study (Sect. 2.1) and the algorithms applied in the simulations (Sect. 2.2).

\subsection{Analysis layout}

In the Earth's atmosphere, LIO signals experience refractive influences, which affect the propagation path and the intensity, as well as attenuating influences which directly affect the intensity. Effects in the received intensity are equivalently imprinted in the observed transmission. Important refractive effects are bending of ray paths and defocusing, caused by the (primarily vertical) gradient and curvature structure of the atmospheric refractivity, as well as scintillations caused by turbulence, i.e. by small-scale random fluctuations of the refractivity. Relevant influences that attenuate the intensity directly include trace gas absorption, aerosol extinction, Rayleigh scattering, cloud extinction, and the influence of solar radiation scattered into the receiver and of the atmosphere's thermal radiation. Furthermore, 1.o.s. wind speed induces a frequency shift resulting in a slightly modified trace species absorption loss.

We investigate the influence of these effects on the transmission and differential transmission of LIO signals. We show most of them for the set of 19 LIO channels (resulting in 13 channel pairs for the retrieval of 10 different species) proposed by Kirchengast et al. (2010) and Kirchengast and Schweitzer (2011), which have been selected on the basis of studies by Schweitzer (2010). The frequencies belonging to these channel pairs and their spectral separation are summarised in Table 1. The quasi-realistic propagation simulations are used to discuss the influence of defocusing (Sect. 3.2), trace gas absorption (Sects. 3.3 and 3.4), aerosol extinction (Sect. 3.5), Rayleigh scattering (Sect. 3.6) and the total influence of all of these atmospheric effects as well as the resulting received signal power in an LIO system (Sect. 3.7). The trace gas absorption is considered from two perspectives: on the one hand, the target species absorption is shown (Sect. 3.3), which is due to the influence of the desired absorber of an absorption channel; on the other hand, the foreign species absorption is investigated (Sect. 3.4), which is the sum of the influences of all unwanted background absorbers (which corresponds to all absorbers in a reference channel, and all absorbers except for the target species in an absorption channel).

The influences studied are inspected by means of the direct atmospheric losses resulting from single channels, and/or by means of differential losses after computing differential transmission from channel pairs (note that atmospheric loss in units $\mathrm{dB}$ is the magnitude of atmospheric transmission in $\mathrm{dB}$, which would have a negative sign). The direct loss is important for the power budget of the intersatellite link, since it degrades the signal-to-noise ratio (SNR) of the received signal. Hence it should be small for all unwanted background effects so that target species absorption is as dominating as possible. On the other hand, the loss due to target species absorption must be significant but also not excessive (which would again degrade SNR too much), in order to enable accurate retrieval of target species concentrations (Kirchengast 
Table 1. Channel pairs investigated in this paper. They are adopted from the ACCURATE satellite mission concept.

\begin{tabular}{lccc}
\hline Species & $\begin{array}{c}\text { Abs. chan. } \\
\bar{v}_{\text {Abs }}\left(\mathrm{cm}^{-1}\right)\end{array}$ & $\begin{array}{c}\text { Ref. chan. } \\
\bar{\nu}_{\text {Ref }}\left(\mathrm{cm}^{-1}\right)\end{array}$ & $\begin{array}{c}\text { Chan. ratio }(\%) \\
100 \cdot \frac{\bar{\nu}_{\text {Abs }}-\bar{\nu}_{\text {Ref }}}{\bar{\nu}_{\text {Ref }}}\end{array}$ \\
\hline $\mathrm{H}_{2} \mathrm{O}-1$ & 4204.840290 & 4227.07 & -0.5259 \\
$\mathrm{H}_{2} \mathrm{O}-2$ & 4775.802970 & 4770.15 & +0.1185 \\
$\mathrm{H}_{2} \mathrm{O}-3$ & 4747.054840 & 4731.03 & +0.3387 \\
$\mathrm{H}_{2} \mathrm{O}-4$ & 4733.045010 & 4731.03 & +0.0426 \\
${ }_{12} \mathrm{CO}_{2}$ & 4771.621441 & 4770.15 & +0.0308 \\
$1^{13} \mathrm{CO}_{2}$ & 4723.414953 & 4731.03 & -0.1610 \\
$\mathrm{C}^{18} \mathrm{OO}$ & 4767.041369 & 4770.15 & -0.0652 \\
$\mathrm{CH}_{4}$ & 4344.163500 & 4322.93 & +0.4912 \\
$\mathrm{~N}_{2} \mathrm{O}$ & 4710.340810 & 4731.03 & -0.4373 \\
$\mathrm{O}_{3}$ & 4029.109610 & 4037.21 & -0.2006 \\
$\mathrm{CO}$ & 4248.317600 & 4227.07 & +0.5027 \\
$\mathrm{HDO}$ & 4237.016320 & 4227.07 & +0.2353 \\
$\mathrm{H}_{2}^{18} \mathrm{O}$ & 4090.871800 & 4098.56 & -0.1876 \\
\hline
\end{tabular}

and Schweitzer, 2011; Proschek et al., 2011a). The differential loss reflects the residual influence of an effect after differencing of the two transmissions (in units $\mathrm{dB}$ ) of a channel pair, which is why it should be as small as possible for all unwanted background effects.

The favourable range of magnitudes of these losses depends on the mission design, above all on the available SNR at the receiver without atmospheric attenuation, i.e. on the ratio of received signal power to the noise-equivalent power (NEP) of the detection system. For the ACCURATE mission this is designed to be at least $34 \mathrm{~dB}$ at $1 \mathrm{~Hz}$ bandwidth (Kirchengast et al., 2010; Kirchengast and Schweitzer, 2011). The total atmospheric loss down to the UTLS bottom $(5 \mathrm{~km})$ should thus not exceed about $21 \mathrm{~dB}$, leaving $13 \mathrm{~dB}$ SNR margin (5\% relative accuracy of signal). The target species absorption loss, the signal portion of interest, should be within about $0.25 \mathrm{~dB}$ and $13 \mathrm{~dB}$, corresponding to an absorption of about $5 \%$ to $95 \%$ (cf. Schweitzer et al., 2011). This leaves about $8 \mathrm{~dB}$ for background losses of which defocusing will use up to about $5 \mathrm{~dB}$ (as seen further below), and $3 \mathrm{~dB}$ or more is thus the remaining margin for other effects like aerosol under post-volcanic conditions. Overall, the direct losses due to background influences should fit into these margins, ideally be below $0.25 \mathrm{~dB}$ (within $5 \%$ perturbation), and in particular their impact in the differential transmission should be, or be correctable to, smaller than $0.005 \mathrm{~dB}$ $(<0.1 \%$ residual error) in order to ensure that their influence on the accuracy of retrieved trace species is negligible. In the case that the direct loss of a background influence exceeds about $0.25 \mathrm{~dB}$, it becomes a potential observable itself and information can be retrieved by applying a suitable algorithm to direct transmission profiles. For LIO signals this will enable to retrieve, for example, cloud layering (Proschek et al., 2011b), aerosol extinction (given significant aerosol load), and turbulence strength profiles.

The bending of the LIO signals is not discussed directly, since the refraction process behind is basically the same as for LMO and GRO signals, which is described by, e.g. Kursinski et al. (2000). Instead, we discuss the difference between the SWIR and MW refractivities, which is relevant for adequate processing of LIO measurements as part of the full LMIO method (Sect. 3.1).

The other atmospheric influences (clouds, turbulence, wind, scattered-solar and terrestrial radiation) are discussed in an introductory, semi-quantitative style in Sect. 3.8, referring to several scientific-technical reports related to which key results will be published elsewhere. The reason is that except for thermal radiation these influences are more complex and therefore require separate papers. Moreover, since these influences exert, except for clouds, small to negligible effects in differential transmission (Schweitzer, 2010; Kirchengast et al., 2010; Kirchengast and Schweitzer, 2011), they are not that fundamental in the context of this paper. Clouds will typically block the whole signal, leading to effectively zero transmission and no received SWIR-laser pulse signal at cloud-contaminated height levels. While it is important to keep this extreme attenuation by clouds in mind, which is separately addressed in mission design and processing, it is not relevant in the context here where we focus on exploitable signals in non-cloudy conditions.

The atmosphere conditions (pressure, temperature, trace gas volume mixing ratios) underlying the propagation simulations were taken from the FASt Atmospheric Signature CODE (FASCODE) atmosphere model (Anderson et al., 1986, provided by A. Dudhia, Univ. of Oxford, UK, via http: //www.atm.ox.ac.uk/RFM/atm); the volume mixing ratio (VMR) for ${ }^{12} \mathrm{CO}_{2}$ therein was updated to a more recent value of $380 \mathrm{ppmv}$. First, geometry data for three occultation events resulting from a constellation of two transmitter (Tx) and two receiver $(\mathrm{Rx})$ satellites in counter-rotating orbits (receiver at $650 \mathrm{~km}$, transmitter at $800 \mathrm{~km}$, circular orbits at true-polar $/ 90^{\circ}$ inclination) were determined using the Mission Analysis and Planning (MAP) system of EGOPS. These events are located in three different latitude regions: one at mid latitudes, where FASCODE standard atmosphere conditions are used (STD: $39.7^{\circ} \mathrm{N}, 114.0^{\circ} \mathrm{W}$ ), one at high latitudes with FASCODE subarctic winter conditions (SAW: $67.5^{\circ} \mathrm{S}, 7.3^{\circ} \mathrm{E}$ ), and one in the tropics with FASCODE tropical conditions (TRO: $1.1^{\circ} \mathrm{N}, 86.0^{\circ} \mathrm{W}$ ). These atmospheric conditions provide representative selections from the range of atmospheric variability (from dry and cold over medium to moist and warm conditions) and are thus suitable to indicate the variability of the atmospheric influences.

For these three occultation events, propagation simulations were performed using the geometric optical ray-tracing algorithm of the EGOPS/xEGOPS system (Syndergaard, 1999; details in Fritzer et al., 2010a). The vertical simulation range was $3 \mathrm{~km}$ to $80 \mathrm{~km}$ and the sampling rate $10 \mathrm{~Hz}$. The 
simulations were arranged for the 19 channels listed in Table 1. Atmospheric losses included in the simulations were those due to defocusing, trace gas absorption, aerosol extinction, and Rayleigh scattering. The atmosphere was assumed to be spherically symmetric and the Earth figure to be an ellipsoid (WGS84, Landolt-Börnstein, 1984).

\subsection{Algorithms for propagation simulation}

\subsubsection{Refractivity}

The refractivity $N$ is described using a streamlined oneequation form of the more sophisticated empirical refractivity formulation of Bönsch and Potulski (1998), which is an improvement of the closely similar optical refractivity formula by Edlén (1966). This formula is valid for optical frequencies including SWIR frequencies $(\lambda>0.5 \mu \mathrm{m})$ and reads, after Proschek et al. (2011a),

$N=\left(c_{1}+\frac{c_{2}}{d_{1}-\frac{1}{\lambda^{2}}}+\frac{c_{3}}{d_{2}-\frac{1}{\lambda^{2}}}\right) \cdot \frac{p}{T}-\epsilon \cdot e$,

where the constants are $c_{1}=23.7104 \mathrm{~K} \mathrm{hPa}^{-1}, c_{2}=6839.34$ $\mathrm{KhPa}^{-1}, \quad c_{3}=45.473 \mathrm{~K} \mathrm{hPa}^{-1}, d_{1}=130.0, \quad d_{2}=38.9$ and $\epsilon=0.038 \mathrm{hPa}^{-1} . \lambda$ is the wavelength of a channel in $\mu \mathrm{m}, p$ the pressure in $\mathrm{hPa}, T$ the temperature in $\mathrm{K}$ and $e$ the water vapour partial pressure in $\mathrm{hPa}$.

The refractivity is responsible for the bending of the LIO ray paths in the atmosphere as well as for the defocusing loss and is discussed below regarding its difference to microwave refractivity as felt by the LMO ray paths. How the refractivity is embedded in the propagation simulations using the geometric-optics ray tracer of EGOPS/xEGOPS is described in detail by Fritzer et al. (2010a).

\subsubsection{Trace species absorption}

The loss along the ray path due to trace species absorption is calculated by applying the Bouguer-Lambert-Beer law, which describes the attenuation of a signal when passing the absorbing air volumes:

$I=I_{0} \cdot e^{-\tau}=I_{0} \cdot e^{-\int \alpha_{\mathrm{m}}(s) \mathrm{d} s}$.

$I_{0}$ and $I$ are the intensities before and after passing the atmosphere, respectively, and $\tau$ is the optical thickness, which is calculated via integration over the volume absorption coefficient $\alpha_{\mathrm{m}}(s)$ (in $\mathrm{m}^{-1}$ ) along the ray path $s$ (in $\mathrm{m}$ ). The integration in the EGOPS/xEGOPS system is done numerically by employing Simpson's trapezoidal rule for approximating the integration along the simulated ray paths.

The absorption coefficient $\alpha_{\mathrm{m}}$ at each ray path point is calculated by use of the Reference Forward Model (RFM), a line-by-line model which was developed under the lead of A. Dudhia, Univ. of Oxford, UK (Edwards, 1996; http://www.atm.ox.ac.uk/RFM). This model was integrated via an interface subroutine into the XEGOPS system (details in Schweitzer et al., 2007; Fritzer et al., 2010a). It uses the absorption line parameters gathered in the Highresolution Transmission (HITRAN) molecular absorption database (distributed by the Harvard-Smithsonian Center for Astrophysics, Cambridge, MA, USA; Rothman et al., 2005, 2009) to model the absorption coefficients at any given SWIR frequency. In the simulations prepared for this study, the HITRAN2004 database (Rothman et al., 2005) was used; the differences to the newer HITRAN2008 database (Rothman et al., 2009) have been checked and found very small and therefore not relevant for the results as discussed here. The pressure, temperature and trace species VMR profiles needed in the absorption coefficient modelling are taken from the FASCODE atmosphere model.

\subsubsection{Aerosol extinction}

The loss due to aerosol extinction is derived by integrating the aerosol extinction coefficient $\epsilon_{\mathrm{a}}(s)$ over the ray path following Eq. (2) (practically by adding $\epsilon_{\mathrm{a}}(s)$ to $\alpha_{\mathrm{m}}(s)$ in the integrand). Thereby, $\epsilon_{\mathrm{a}}(s)$ is calculated using a semiempirical model which we developed especially for XEGOPS (Schweitzer et al., 2008). Briefly, the model uses three climatologies for the aerosol extinction coefficient at a wavelength of $1020 \mathrm{~nm}$, which we compiled on the basis of more than a decade of monthly data from the Stratospheric Aerosol and Gas Experiment II (SAGE II) instrument (Thomason and Peter, 2006). The climatologies are two-dimensional fields containing 71 height levels ( $5 \mathrm{~km}$ to $40 \mathrm{~km}, 0.5 \mathrm{~km}$ steps) and 36 latitude bands $\left(5^{\circ}\right.$ broad, $90^{\circ} \mathrm{S}$ to $\left.90^{\circ} \mathrm{N}\right)$. The model interpolates to arbitrary latitude and height locations within these fields (and extrapolates beyond their boundaries in a meaningful way). The three climatologies reflect the atmospheric variability of the aerosol extinction coefficient in three typical aerosol conditions: background, medium, and volcanic aerosol load.

The extinction coefficient at other frequencies is derived from these climatologies by applying the so-called Ångström formula,

$\epsilon_{\mathrm{a}, \lambda}=\epsilon_{\mathrm{a}, \lambda_{0}} \cdot\left(\frac{\lambda_{0}}{\lambda}\right)^{A}$,

where $\epsilon_{\mathrm{a}, \lambda}$ is the extinction coefficient (in $\mathrm{m}^{-1}$ ) at the desired wavelength $\lambda, \epsilon_{\mathrm{a}, \lambda_{0}}$ is the extinction coefficient tabulated/interpolated in the climatology (valid at $\lambda_{0}=1020 \mathrm{~nm}$ ), and $A$ is the Angström exponent. For the latter, we also developed a two-dimensional climatology (a field with the same latitude and height resolution as used for the extinction coefficient) from the ratio of SAGE II extinction coefficient climatologies for the wavelengths of $525 \mathrm{~nm}$ and $1020 \mathrm{~nm}$. Since the variation of this Angström exponent depends comparatively weakly on the aerosol load, one climatology was considered sufficient. 
With these settings, the empirical model is reasonably valid for calculation of aerosol extinction coefficients within $500 \mathrm{~nm}$ to $2500 \mathrm{~nm}$; see in addition to Thomason and Peter (2006) also Thomason and Taha (2003) for discussion of the SAGE II data. Details on how the climatologies have been compiled are presented by Schweitzer et al. (2008) and a detailed description of the aerosol model as implemented in xEGOPS can be found in Fritzer et al. (2010a).

\subsubsection{Rayleigh scattering}

The loss due to Rayleigh scattering is derived by integrating the respective scattering coefficient along the ray path following Eq. (2) (practically by also adding the Rayleigh scattering coefficient $\sigma_{\mathrm{r}}(s)$ to $\alpha_{\mathrm{m}}(s)$ ). $\sigma_{\mathrm{r}}(s)\left(\right.$ in $\left.^{-1}\right)$ is defined after Salby (1996) by

$\sigma_{\mathrm{r}}=\frac{32 \cdot \pi^{3} \cdot(n-1)^{2}}{3 \cdot \lambda^{4} \cdot N_{\mathrm{air}}}$,

where $n=1+10^{-6} N$ is the refractive index, $\lambda$ is the wavelength in $\mathrm{m}$ and $N_{\text {air }}$ is the number density of the air in $\mathrm{m}^{-3}$; details on how the Rayleigh scattering is implemented in xEGOPS are included in Fritzer et al. (2010a).

\section{Results and discussion}

\subsection{Difference between IR and MW refractivity}

As discussed in the introduction, the LMIO method exploits MW and SWIR signals which are simultaneously transmitted between two LEO satellites. Since the atmospheric refractivity is slightly different for MW and SWIR frequencies, increasingly so in moist air, the signals propagate along somewhat different ray paths (as indicated in Fig. 1). This leads to different tangent points (i.e. ray perigees) of the MW and SWIR propagation paths. Hence, profiles derived from LMO and LIO data are associated with a different tangent height grid when the measurements are taken at the same time grid. It is important to account for this difference in the retrieval of LIO products, which needs the LMO retrieval results as input (Proschek et al., 2011a).

The main reason for the difference between the refractivities is that the MW refractivity significantly grows with increasing amount of water vapour while the SWIR refractivity is virtually independent of water vapour (Eq. 1). This occurs because the $\mathrm{H}_{2} \mathrm{O}$ molecules with their permanent electric dipole moment orientate themselves in the comparatively slowly oscillating electric field of the MW signals, leading to a significant orientation polarisation term (second term of Smith-Weintraub formula, see, e.g. Schweitzer et al., 2011), while the SWIR frequencies are too high for the dipole orientations to follow. As shown by Schweitzer (2010), presence of water vapour decreases the SWIR refractivity by less than $0.1 \%$ at $5 \mathrm{~km}$, even in very high moisture.

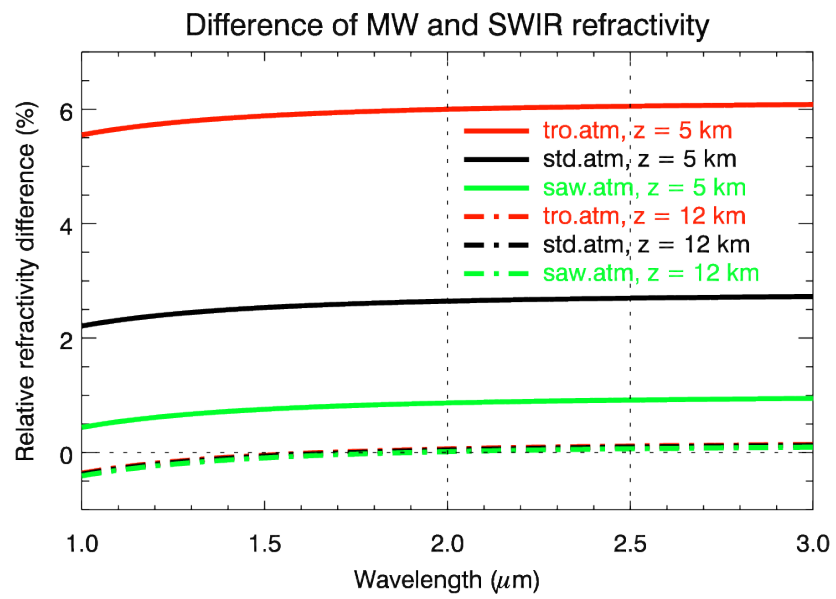

Fig. 2. Relative difference between the MW refractivity (SmithWeintraub formula) and the SWIR refractivity (improved Edlén formula). The differences are shown for the FASCODE TRO, STD and SAW atmospheres at $5 \mathrm{~km}$ and $12 \mathrm{~km}$ (atmospheric conditions, $\mathrm{p} / \mathrm{T} / \mathrm{e}$ in $\mathrm{hPa} / \mathrm{K} / \mathrm{hPa}$, for TRO $5 \mathrm{~km}$ : 559.0/270.3/1.87; STD $5 \mathrm{~km}$ : 540.5/255.7/0.76; SAW 5 km: 515.8/240.9/0.22; TRO $12 \mathrm{~km}$ : 213.0/223.6/0.01; STD $12 \mathrm{~km}$ : 194.0/216.7/0.00; SAW $12 \mathrm{~km}$ : $176.6 / 217.2 / 0.00)$.

Favourably, the difference between the MW and SWIR refractivities is very small under most atmospheric conditions. This can be seen from Fig. 2 which shows the relative difference of the refractivities in different representative atmospheric conditions for wavelengths between $1 \mu \mathrm{m}$ and $3 \mu \mathrm{m}$. The MW refractivity is represented by the Smith-Weintraub formula that disregards dispersion which is negligible over the relevant LMO wavelength range (e.g. Schweitzer et al., 2011), the SWIR refractivity by the improved Edlén formula, Eq. (1). The difference is very stable for wavelengths greater than about $1.6 \mu \mathrm{m}$, which indicates that dispersive effects are minor in this spectral region. The region used by ACCURATE extends from $2 \mu \mathrm{m}$ to $2.5 \mu \mathrm{m}$. The relative refractivity difference in this region is below $0.1 \%$ for heights above about $9 \mathrm{~km}$ (high latitudes) to $13 \mathrm{~km}$ (tropics) (compare also Schweitzer, 2010). Below, it grows depending on the moisture content up to about $1 \%$ in SAW conditions, $2.75 \%$ in STD and $6 \%$ in TRO conditions at $5 \mathrm{~km}$.

These differences in the refractivities lead to different bending of the MW and SWIR ray paths. The MW rays are bent stronger than the SWIR rays (as depicted in Fig. 1), which is why the MW tangent point heights are higher than the SWIR tangent point heights when comparing them at a specific time during the occultation event. In particular, the separation of the two tangent point heights at a given time related to a height of $5 \mathrm{~km}$ is about $0.15 \mathrm{~km}$ in SAW conditions, $0.5 \mathrm{~km}$ in STD conditions, and $1 \mathrm{~km}$ in TRO conditions. At a time related to around $10 \mathrm{~km}$, the difference of the tangent point heights is already reduced to a few metres (about $5 \mathrm{~m}$ in SAW, $20 \mathrm{~m}$ in STD, $60 \mathrm{~m}$ in TRO). Above about $12 \mathrm{~km}$ 
to $13 \mathrm{~km}$, the difference is negligible, i.e. within the vertical geolocation accuracy requirement of better than $10 \mathrm{~m}$ under all conditions (Kirchengast et al., 2010).

Hence, the MW and SWIR parts of LMIO measurements can in principle be combined directly above about $9 \mathrm{~km}$ to $13 \mathrm{~km}$, using the MW heights also for the SWIR data. Below, the difference between the tangent point height profiles must be calculated and incorporated when retrieving LMIO products. Details of a respective algorithm are described by Proschek et al. (2011a), where, for completeness and for avoiding ad-hoc threshold heights near $13 \mathrm{~km}$, the SWIR height grid is consistently determined over the complete occultation event height range, down to centimetre level differences of MW and SWIR heights. These residual differences of the slightly higher Smith-Weintraub refractivity in dry air compared to the improved-Edlén one (at the $5 \times 10^{-4}$ level) are of no significant relevance since they are at the level of uncertainty of the empirical refractivity constants (see e.g. Healy, 2011). Future refined estimates of the refractivity constants, or of the related molecular polarisabilities, at an accuracy of $<1 \times 10^{-4}$ will be worthwhile in order to fully quantify the level of consistency of the MW and SWIR refractivities at this level of accuracy.

\subsection{Influence of defocusing}

Defocusing is attributable to changing vertical gradients, i.e. the second derivative, of the atmospheric refractivity. These changes cause differential bending and therefore divergence (sometimes, for limited time spans, convergence) of adjacent, initially parallel ray paths. Such divergence leads to an attenuation of the signal intensity (Kursinski et al., 2000), intermittent convergences lead to oscillations of defocusing loss.

Defocusing affects both, MW and SWIR signals, in the same way and leads to a significant loss reducing the SNR of the received intensity. Hence it is an important factor in computations of available SNR, especially in the troposphere. As visible in Fig. 3, which shows examples of the defocusing loss in three representative atmospheric conditions, the loss typically reaches about $5 \mathrm{~dB}$ at $5 \mathrm{~km}$ and decreases upwards. Around $15 \mathrm{~km}$, it is declined to about $3 \mathrm{~dB}$ and at about $30 \mathrm{~km}$ it falls below the lower useful-signal limit of $0.25 \mathrm{~dB}$. The oscillating features in the profiles stem from strong temperature gradient changes around the tropopause leading to sharp changes of the vertical gradient of the refractivity. The dispersion of defocusing is negligible in the SWIR spectral range which is why the defocusing loss looks equal for all frequencies listed in Table 1 . This negligible dependence on frequency is useful, since even though the SNR is somewhat degraded by the defocusing loss, its absolute influence can be eliminated in trace species retrieval simply by employing the differential transmission of channel pairs.

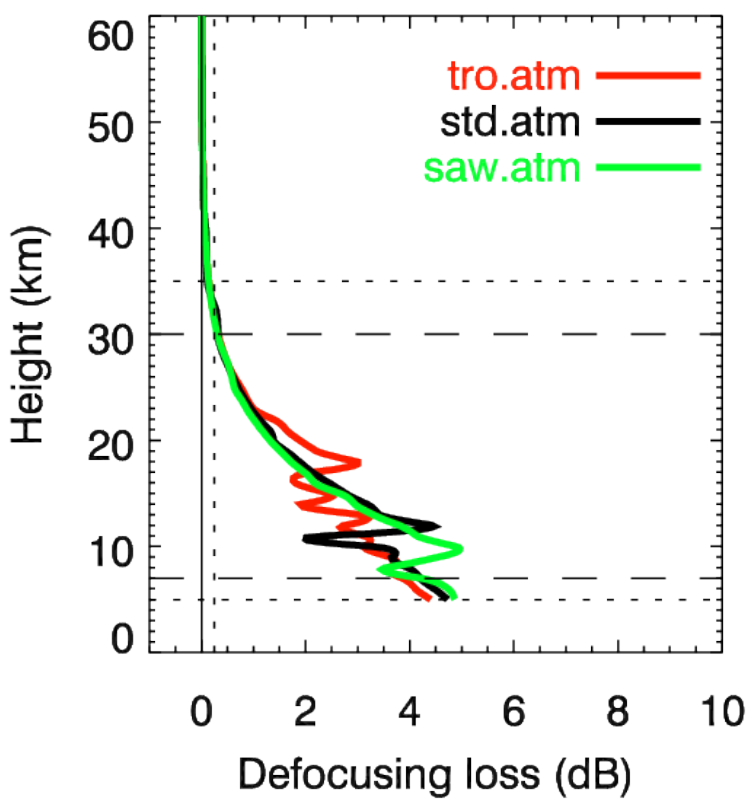

Fig. 3. Defocusing loss for SWIR channels in the FASCODE SAW (green), STD (black), TRO (red) atmospheres. The vertical dotted line marks the boundary of the lower useful-signal limit of $0.25 \mathrm{~dB}$. The horizontal dotted and dashed lines mark target and threshold requirements, respectively, regarding the vertical range within which trace species shall be retrieved (Kirchengast and Schweitzer, 2011).

\subsection{Influence of target species absorption}

The term target species absorption names the portion of the molecular gas absorption in an LIO absorption channel induced by the species of interest (which is the species whose VMR shall be retrieved); all other species contribute to the unwanted foreign species absorption. Regarding LIO reference channels, all absorbing species are perturbing, which is why they are all considered foreign there, so that in this case the foreign species absorption is equal to the total gas absorption.

As discussed in Sect. 2.1, the target species absorption loss should fall within a certain favourable range $(0.25 \mathrm{~dB}$ to $13 \mathrm{~dB}$ for the ACCURATE mission design) to ensure receiving good signal over noise, which can be exploited for accurate trace species retrieval. The lower boundary means to ensure sufficient signal (at least about $5 \%$ absorption of transmitted signal), the upper boundary to ensure sufficient SNR (at least about $5 \%$ of transmitted signal left after absorption). The total absorption of the reference channels should be as small as possible and contain the contribution of broadband far-line-wing or continuum absorption only, to minimise the influence of background absorption on retrieval products when using differential transmission.

Figure 4 presents the target species absorption for absorption channels and the total absorption for reference channels. Included are all 19 channels (13 channel pairs) listed in Table 1, which are part of the ACCURATE mission design. 

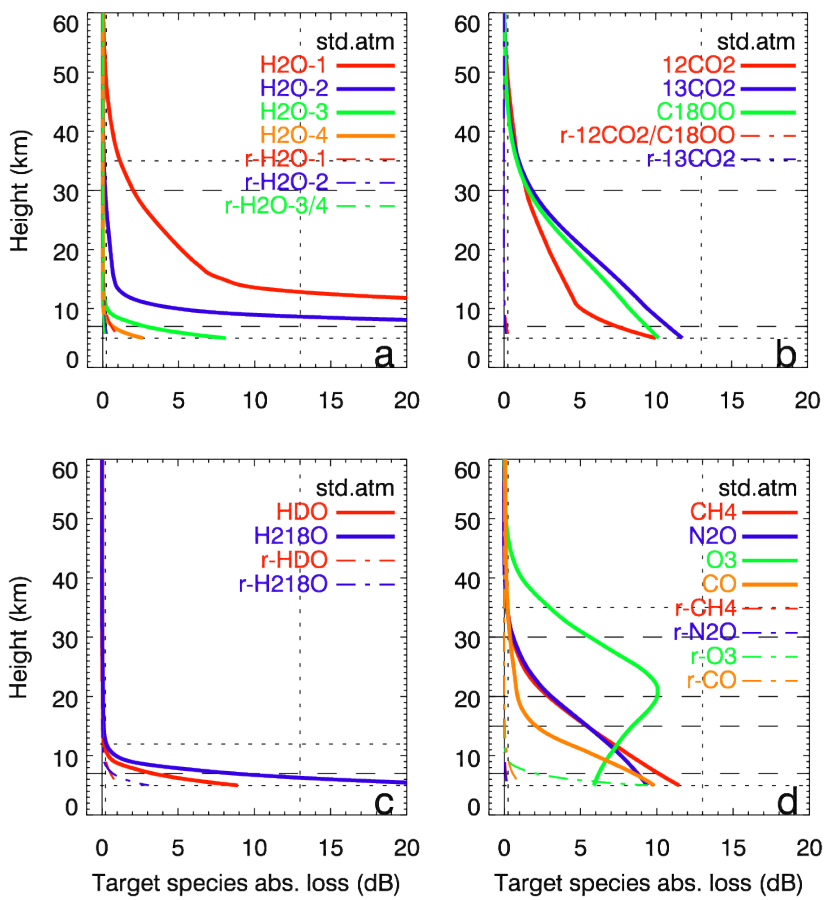

Fig. 4. Target species absorption loss for the 13 absorption channels and total absorption loss for the six reference channels listed in Table 1. The situation is shown for the FASCODE STD atmosphere. Absorption channels are marked by solid lines, reference channels (at or near $0 \mathrm{~dB}$ ) by dashed-dotted lines. The vertical dashed lines mark the lower and upper boundary of favourable signal range. The horizontal dotted and dashed lines mark target and threshold requirements, respectively, regarding the vertical range within which trace species shall be retrieved.

Figure 4a shows the channels used to retrieve water vapour. Four absorption channels $\left(\mathrm{H}_{2} \mathrm{O}-1, \mathrm{H}_{2} \mathrm{O}-2, \mathrm{H}_{2} \mathrm{O}-3\right.$, $\left.\mathrm{H}_{2} \mathrm{O}-4\right)$ are needed to cover the whole UTLS region and the atmospheric variability under all atmospheric conditions. The channel most sensitive to $\mathrm{H}_{2} \mathrm{O}$ absorption, $\mathrm{H}_{2} \mathrm{O}-1$, is useful from about $13 \mathrm{~km}$ upwards to above $40 \mathrm{~km}$ under all atmospheric conditions. On the contrary, the least sensitive channel, $\mathrm{H}_{2} \mathrm{O}-4$, is useless in the UTLS in weakly moist conditions as SAW and STD. But it becomes important below about $7 \mathrm{~km}$ under wet TRO conditions (a detailed illustration of the sensitivities in different atmospheric conditions can be found in Schweitzer, 2010). The medium-sensitive channels cover the region in between the outer channels, where $\mathrm{H}_{2} \mathrm{O}$ 2 captures the altitudes from about $7 \mathrm{~km}$ to $10 \mathrm{~km}$ upwards (up to about $25 \mathrm{~km}$ ), $\mathrm{H}_{2} \mathrm{O}-3$ becomes important below about $7 \mathrm{~km}$ to $10 \mathrm{~km}$. Hence, the overlapping area of the medium sensitive channels is relatively small. This might result in slightly reduced but still high retrieval accuracy (within $4 \%$ individual profile error; Proschek et al., 2011a) around $8 \mathrm{~km}$ to $10 \mathrm{~km}$ under unfavourable atmospheric conditions.

The reference channels used to retrieve water vapour (named by $\mathrm{r}$-〈species $\rangle$ in the figures) favourably show low sensitivity to atmospheric absorption. The absorption loss does not exceed $0.25 \mathrm{~dB}$ in the height ranges where they are employed. This applies also for the TRO and SAW conditions (cf. Schweitzer, 2010).

Figure $4 \mathrm{~b}$ shows the situation for the channels used to retrieve the three $\mathrm{CO}_{2}$ isotopes ${ }^{12} \mathrm{CO}_{2},{ }^{13} \mathrm{CO}_{2}$ and $\mathrm{C}^{18} \mathrm{OO}$. The sensitivities of the absorption channels cover the whole UTLS region, also in SAW and TRO conditions (Schweitzer, 2010). Hence one channel for each species is sufficient to allow their retrieval under all atmospheric conditions. The sensitivities of the ${ }^{13} \mathrm{CO}_{2}$ and $\mathrm{C}^{18} \mathrm{OO}$ channels decrease very evenly with decreasing height and show very low sensitivity to ambient atmospheric (temperature, pressure) conditions. This behaviour is ideal from a scientific point of view since this minimises errors in the retrieval (e.g. errors from the LMO-retrieved pressure and temperature). The sensitivity of the ${ }^{12} \mathrm{CO}_{2}$ channel depends more significantly on the atmospheric conditions, especially on the temperature (Schweitzer, 2010). This is because the lower state energy of the respective ${ }^{12} \mathrm{CO}_{2}$ absorption transition is rather high (it is still the best ${ }^{12} \mathrm{CO}_{2}$ line choice in the targeted SWIR range), which causes the transition to be notably dependent on pressure and temperature. Since pressure and temperature from LMO are expected to be very accurate (pressure better than $0.2 \%$, temperature better than $0.5 \mathrm{~K}$; Schweitzer et al., 2011), the ${ }^{12} \mathrm{CO}_{2}$ VMR retrieval results will still be very accurate (Proschek et al., 2011a; for further improvement they can also be combined with ${ }^{13} \mathrm{CO}_{2}$ retrieval results).

The reference channels used to retrieve the three $\mathrm{CO}_{2}$ isotopes have very low sensitivity to total atmospheric absorption. The loss exceeds $0.25 \mathrm{~dB}$ only very little below about $6 \mathrm{~km}$ to $7 \mathrm{~km}$. The behaviour is very similar under all atmospheric conditions.

The channels used for retrieving the $\mathrm{H}_{2} \mathrm{O}$ isotopes HDO and $\mathrm{H}_{2}{ }^{18} \mathrm{O}$ are presented in Fig. 4c. The vertical range of sensitivity of the absorption channels is quite limited in the STD atmosphere and also under SAW and TRO conditions (Schweitzer, 2010). In particular, significant absorption only occurs below about $10 \mathrm{~km}$ to $12 \mathrm{~km}$. This is due to the very low concentrations of $\mathrm{HDO}$ and $\mathrm{H}_{2}{ }^{18} \mathrm{O}$ in the atmosphere and especially in the stratosphere. Below $10 \mathrm{~km}$, the absorption steeply increases with decreasing height, for $\mathrm{H}_{2}{ }^{18} \mathrm{O}$ a bit faster than for HDO. As a consequence, the absorption exceeds the upper limit of $13 \mathrm{~dB}$ already at heights slightly above $5 \mathrm{~km}$ and one must reckon that the signal is lost in moist air conditions. For example, the target species absorption of $\mathrm{H}_{2}{ }^{18} \mathrm{O}$ exceeds the $13 \mathrm{~dB}$ limit at a height of about $8 \mathrm{~km}$ under TRO conditions.

The reference channels used for retrieving the $\mathrm{H}_{2} \mathrm{O}$ isotopes also show a relatively high sensitivity to background absorption. This especially applies to the $\mathrm{r}-\mathrm{H}_{2}{ }^{18} \mathrm{O}$ channel, which reaches a loss of about $3 \mathrm{~dB}$ (SAW) to $8 \mathrm{~dB}$ (TRO) at $5 \mathrm{~km}$ (Schweitzer, 2010). This absorption is mainly due to $\mathrm{H}_{2} \mathrm{O}$. The variability of the $\mathrm{r}-\mathrm{HDO}$ channel is comparatively small; the absorption loss varies only within about $1 \mathrm{~dB}$ and 
$2 \mathrm{~dB}$ at $5 \mathrm{~km}$, since the major part stems from $\mathrm{CH}_{4}$ which is well-mixed in the UTLS.

All in all, the channels for measuring the $\mathrm{H}_{2} \mathrm{O}$ isotopes are not ideal because of their vertical limitation in sensitivity and the relatively high influence of foreign species (cf. also Sect. 3.4). But these channels were the most suitable ones we could find for these isotopes in the SWIR $2 \mu \mathrm{m}$ to $2.5 \mu \mathrm{m}$ region. Therefore, the $\mathrm{H}_{2} \mathrm{O}$ isotopes are considered as species of secondary interest in the ACCURATE mission concept. Meaningful retrieval of the VMR of these species is only possible within about $5 \mathrm{~km}$ to $12 \mathrm{~km}$; this range is limited further in increasingly moist atmospheric conditions. However, since the upper tropospheric $\mathrm{H}_{2} \mathrm{O}$ isotopes are important tracers of moistening and precipitation processes in the water cycle and measurements of them are rare, even these restricted profiles may have significant value for atmosphere and climate science.

Figure $4 \mathrm{~d}$ shows the target species absorption losses for the channels used to retrieve $\mathrm{CH}_{4}, \mathrm{~N}_{2} \mathrm{O}, \mathrm{O}_{3}$ and $\mathrm{CO}$. All four absorption channels show a very good sensitivity throughout the UTLS region under STD conditions. Since the variability is very small under different atmospheric conditions, this is also true in the SAW and TRO atmospheres (Schweitzer, 2010). Characteristic is the behaviour of the $\mathrm{O}_{3}$ absorption, which reflects the shape of the atmospheric $\mathrm{O}_{3}$ concentration that peaks in the lower stratosphere.

The sensitivity of the reference channels $\mathrm{r}-\mathrm{CH}_{4}$ and $\mathrm{r}$ $\mathrm{N}_{2} \mathrm{O}$ to background absorption is very small. Their absorption loss is typically below $0.25 \mathrm{~dB}$ and exceeds this limit just marginally beneath about $6 \mathrm{~km}$ under TRO atmospheric conditions (Schweitzer, 2010). In contrast, the $\mathrm{r}-\mathrm{O}_{3}$ and $\mathrm{r}$ $\mathrm{CO}$ channels are significantly influenced by background absorbers. The r-CO is the same as the r-HDO channel and was already discussed above. The absorption of the $\mathrm{r}-\mathrm{O}_{3}$ channel is mainly caused by $\mathrm{H}_{2} \mathrm{O}$ and therefore varies strongly under different moisture conditions; at $5 \mathrm{~km}$ from about $2.5 \mathrm{~dB}$ under SAW over $9.5 \mathrm{~dB}$ under STD to more than $20 \mathrm{~dB}$ under TRO conditions (see Sect. 3.4). Also the vertical variation is high and the loss steeply increases and exceeds the $0.25 \mathrm{~dB}$ boundary from about $10 \mathrm{~km}$ to $11 \mathrm{~km}$ downwards.

Overall the sensitivities of the absorption channels investigated here to the respective target species are very good (found most suitable by Schweitzer, 2010, and Kirchengast and Schweitzer, 2011 and used as the baseline for the ACCURATE mission; Kirchengast et al., 2010). They provide enough sensitivity to allow for accurate retrieval of eight trace species $\left(\mathrm{H}_{2} \mathrm{O}, \mathrm{CO}_{2},{ }^{13} \mathrm{CO}_{2}, \mathrm{C}^{18} \mathrm{OO}, \mathrm{CH}_{4}, \mathrm{~N}_{2} \mathrm{O}, \mathrm{O}_{3}\right.$, $\mathrm{CO})$ throughout the UTLS region under all reasonable noncloudy atmospheric conditions. Two further species, HDO and $\mathrm{H}_{2}{ }^{18} \mathrm{O}$, which have a very low concentration in the atmosphere, can be retrieved within about $5 \mathrm{~km}$ to $12 \mathrm{~km}$.

\subsection{Influence of foreign species absorption}

As explained at the beginning of Sect. 3.3, foreign species absorption is the total absorption from all unwanted (foreign) species affecting a channel. Since foreign species disturb the absorptive signature of the target species, and thus may perturb the trace species retrieval, it is important to select channels which are as much as possible free from the influence of foreign species. In reality, however, foreign species absorption cannot be avoided entirely, which is why a second criterion for the selection of absorption and reference channels is that the influence of foreign species absorption is significantly reduced in the differential transmission.

The remaining differential foreign species losses should ideally be below $0.005 \mathrm{~dB}$ (corresponding to below $0.1 \%$ differential absorption); a hard criterion which can only be achieved at heights from about $15 \mathrm{~km}$ to $25 \mathrm{~km}$ upwards. In practice, one should therefore try to keep the differential foreign species absorption loss below $0.25 \mathrm{~dB}$ (below $5 \%$ ). The remaining influence can be co-modelled during the retrieval process to correct the residual foreign species absorption loss to the $0.01 \mathrm{~dB}$ level, with the remaining systematic error component below $0.005 \mathrm{~dB}$ (for details of this correction in trace species retrieval see Proschek et al., 2011a).

Figure 5 displays the foreign species absorption losses remaining in the differential transmissions for the selected channel pairs of Table 1. The behaviour is shown in the FASCODE STD atmosphere, which is well representative since dependence on ambient atmospheric conditions is weak for most species so that the losses are essentially the same as in the STD conditions (Schweitzer, 2010). Differential foreign species absorption losses showing significant variability dependent on atmospheric conditions, which concerns $\mathrm{O}_{3}$ and $\mathrm{H}_{2}{ }^{18} \mathrm{O}$, are additionally illustrated in FASCODE SAW and TRO conditions in Fig. 6.

Details on which specific foreign species contribute to what degree to the foreign species losses are listed in Table 2. Practically speaking, for all those channel pairs being affected by no major influence of $\mathrm{H}_{2} \mathrm{O}$, the losses weakly depend on atmospheric conditions, since all other foreign species of relevance exhibit at any height level comparatively low variability of their concentration. $\mathrm{O}_{3}$ and $\mathrm{H}_{2}{ }^{18} \mathrm{O}$ channel pairs are those, where major influence of $\mathrm{H}_{2} \mathrm{O}$ below about $10 \mathrm{~km}$ was unavoidable even for the best possible SWIR channel selections.

The residual foreign species absorption losses for the channel pairs used to retrieve $\mathrm{H}_{2} \mathrm{O}$ are shown in Fig. 5a. Their influence is negligible (i.e. losses below $0.005 \mathrm{~dB}$ ) from about $20 \mathrm{~km}$ upwards. Below the losses gradually increase but stay within $0.25 \mathrm{~dB}$ in those height ranges, where the channels are used. That is the $\mathrm{H}_{2} \mathrm{O}-2$ channel pair, where the loss transgresses $0.25 \mathrm{~dB}$ at about $8 \mathrm{~km}$, has its main range for contributing to $\mathrm{H}_{2} \mathrm{O}$ retrieval from $8 \mathrm{~km}$ to $25 \mathrm{~km}$ (Proschek et al., 2011a). Dependence on ambient atmospheric conditions is weak for these channels as seen in 

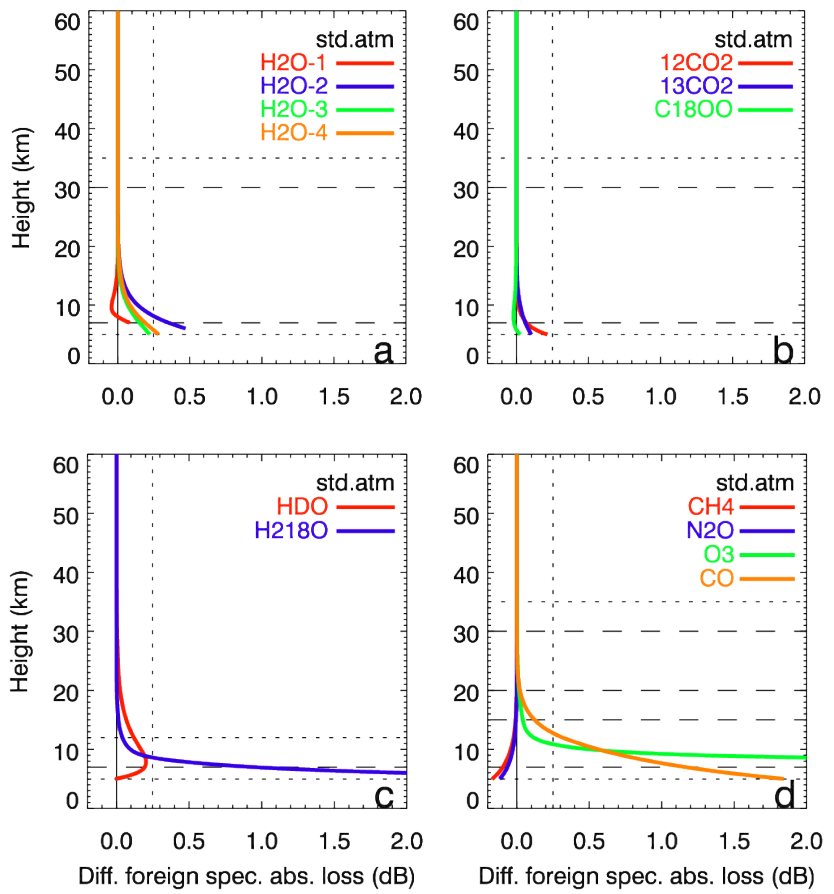

Fig. 5. Differential foreign species absorption loss for the 13 channel pairs listed in Table 1, for the FASCODE STD atmosphere. The vertical dotted line marks the boundary where the foreign species loss, if transgressing it, enters into the favourable range for target species loss. The horizontal dotted and dashed lines mark target and threshold requirements, respectively, regarding the vertical range within which trace species shall be retrieved.

Table 2; the major influence of $\mathrm{HDO}$ on $\mathrm{H}_{2} \mathrm{O}-1$ is restricted to below $10 \mathrm{~km}$, which is outside the main range of this "stratospheric" $\mathrm{H}_{2} \mathrm{O}$ channel that is exploited above $10 \mathrm{~km}$ only.

The residual foreign species losses for the channel pairs used to retrieve the $\mathrm{CO}_{2}$ isotopes ${ }^{12} \mathrm{CO}_{2},{ }^{13} \mathrm{CO}_{2}$ and $\mathrm{C}^{18} \mathrm{OO}$ are shown in Fig. 5b. They are smaller than $0.005 \mathrm{~dB}$ from about $15 \mathrm{~km}$ upwards. Below the losses increase but stay within the $0.25 \mathrm{~dB}$ boundary. The behaviour for the ${ }^{13} \mathrm{CO}_{2}$ and $\mathrm{C}^{18} \mathrm{OO}$ channel pairs is very stable under all atmospheric conditions (cf. Schweitzer, 2010). Only the ${ }^{12} \mathrm{CO}_{2}$ channel shows a higher but limited sensitivity to atmospheric variability, leading to a differential foreign species absorption loss of up to $0.5 \mathrm{~dB}$ at $5 \mathrm{~km}$ under TRO conditions; the reason is some small influence of $\mathrm{H}_{2} \mathrm{O}$ (Table 2).

The residual foreign species losses for the water isotopes $\mathrm{HDO}$ and $\mathrm{H}_{2}{ }^{18} \mathrm{O}$ are shown in Fig. 5c. The loss resulting for the HDO channel pair is below $0.005 \mathrm{~dB}$ from about $25 \mathrm{~km}$ upwards, increases below to a maximum of about $0.2 \mathrm{~dB}$ near $7 \mathrm{~km}$ and decreases again beneath to near zero at $5 \mathrm{~km}$. This is due to a different vertical behaviour of the foreign species absorption losses of the absorption and reference channel. Dependence on ambient atmospheric conditions is weak since the main influence stems from $\mathrm{CH}_{4}$ (Table 2), which exhibits low variability globally in the UTLS. The
Table 2. Species mainly contributing to foreign species absorption, ordered according to their influence in FASCODE STD conditions at $5 \mathrm{~km}$. Species without parentheses have major influence (larger or around $1 \mathrm{~dB}$ ), squared brackets mark small influence (below $0.5 \mathrm{~dB}$ to $1 \mathrm{~dB}$ ), round brackets very small influence (below $0.25 \mathrm{~dB}$ ). These influence limits apply under all atmospheric conditions including TRO conditions.

\begin{tabular}{|c|c|}
\hline Channel & Absorbing foreign species \\
\hline $\mathrm{H}_{2} \mathrm{O}-1$ & $\mathrm{HDO},\left[\mathrm{CH}_{4}\right],(\mathrm{CO})$ \\
\hline $\mathrm{H}_{2} \mathrm{O}-2$ & {$\left[{ }^{12} \mathrm{CO}_{2}, \mathrm{C}^{18} \mathrm{OO}\right]$} \\
\hline $\mathrm{H}_{2} \mathrm{O}-3$ & {$\left[\mathrm{~N}_{2} \mathrm{O}\right],\left({ }^{12} \mathrm{CO}_{2}\right)$} \\
\hline $\mathrm{H}_{2} \mathrm{O}-4$ & $\left({ }^{12} \mathrm{CO}_{2},{ }^{13} \mathrm{CO}_{2}, \mathrm{C}^{18} \mathrm{OO}\right)$ \\
\hline${ }^{12} \mathrm{CO}_{2}$ & {$\left[\mathrm{H}_{2} \mathrm{O}, \mathrm{C}^{18} \mathrm{OO}\right]$} \\
\hline${ }^{13} \mathrm{CO}_{2}$ & {$\left[\mathrm{H}_{2}{ }^{18} \mathrm{O}\right],\left(\mathrm{H}_{2} \mathrm{O}\right)$} \\
\hline $\mathrm{C}^{18} \mathrm{OO}$ & $\left({ }^{12} \mathrm{CO}_{2},{ }^{13} \mathrm{CO}_{2}, \mathrm{H}_{2} \mathrm{O}\right)$ \\
\hline $\mathrm{CH}_{4}$ & $\left(\mathrm{H}_{2} \mathrm{O}\right)$ \\
\hline $\mathrm{N}_{2} \mathrm{O}$ & $\left(\mathrm{H}_{2} \mathrm{O}\right)$ \\
\hline $\mathrm{O}_{3}$ & $\mathrm{H}_{2} \mathrm{O}, \mathrm{HDO},\left[\mathrm{H}_{2}{ }^{18} \mathrm{O}\right],\left(\mathrm{CH}_{4}\right)$ \\
\hline $\mathrm{CO}$ & $\mathrm{CH}_{4},\left[\mathrm{H}_{2} \mathrm{O}\right],(\mathrm{HDO})$ \\
\hline HDO & $\mathrm{CH}_{4},\left[\mathrm{H}_{2} \mathrm{O}\right]$ \\
\hline $\mathrm{H}_{2}{ }^{18} \mathrm{O}$ & $\mathrm{H}_{2} \mathrm{O},\left[\mathrm{CH}_{4}\right]$ \\
\hline $\mathrm{r}-\mathrm{O}_{3}$ & $\mathrm{H}_{2} \mathrm{O},(\mathrm{HDO})$ \\
\hline $\mathrm{r}-\mathrm{H}_{2}{ }^{18} \mathrm{O}$ & $\mathrm{H}_{2} \mathrm{O},\left[\mathrm{CH}_{4}\right]$ \\
\hline $\mathrm{r}-\mathrm{H}_{2} \mathrm{O}-1, \mathrm{r}-\mathrm{HDO}, \mathrm{r}-\mathrm{CO}$ & $\mathrm{CH}_{4},\left[\mathrm{H}_{2} \mathrm{O}\right],(\mathrm{CO})$ \\
\hline $\mathrm{r}-\mathrm{CH}_{4}$ & $\left(\mathrm{CH}_{4}, \mathrm{H}_{2} \mathrm{O}\right)$ \\
\hline $\mathrm{r}-\mathrm{N}_{2} \mathrm{O}, \mathrm{r}-{ }^{13} \mathrm{CO}_{2}, \mathrm{r}-\mathrm{H}_{2} \mathrm{O}-3 / 4$ & $\left({ }^{12} \mathrm{CO}_{2},{ }^{13} \mathrm{CO}_{2}, \mathrm{C}^{18} \mathrm{OO}\right)$ \\
\hline $\mathrm{r}-^{12} \mathrm{CO}_{2}, \mathrm{r}-\mathrm{C}^{18} \mathrm{OO}, \mathrm{r}-\mathrm{H}_{2} \mathrm{O}-2$ & $\left({ }^{12} \mathrm{CO}_{2}, \mathrm{C}^{18} \mathrm{OO},{ }^{13} \mathrm{CO}_{2}\right)$ \\
\hline
\end{tabular}

foreign loss for the $\mathrm{H}_{2}{ }^{18} \mathrm{O}$ channel pair stems mainly from $\mathrm{H}_{2} \mathrm{O}$, which is why this loss varies strongly under different atmospheric conditions as can be seen from Fig. 6. The loss exceeds $0.005 \mathrm{~dB}$ from about $15 \mathrm{~km}$ downwards and reaches at $5 \mathrm{~km}$ about $1 \mathrm{~dB}$ under $\mathrm{SAW}, 4 \mathrm{~dB}$ under $\mathrm{STD}$ and $10.5 \mathrm{~dB}$ under TRO conditions. For this species it is thus particularly essential to co-model and correct the influence of the foreign species during the retrieval.

Figure $5 \mathrm{~d}$ shows the residual foreign species losses for the channels used to retrieve $\mathrm{CH}_{4}, \mathrm{~N}_{2} \mathrm{O}, \mathrm{O}_{3}$ and $\mathrm{CO}$. The losses for $\mathrm{CH}_{4}$ and $\mathrm{N}_{2} \mathrm{O}$ are very small, exceeding the $0.005 \mathrm{~dB}$ boundary below about $15 \mathrm{~km}$ and reaching a maximum value of below $0.2 \mathrm{~dB}$ at $5 \mathrm{~km}$. Dependence on atmospheric conditions is weak since cross-sensitivity to $\mathrm{H}_{2} \mathrm{O}$ is very small (Table 2). The loss for $\mathrm{CO}$ is also very similar under all atmospheric conditions, even though this one exceeds the $0.25 \mathrm{~dB}$ boundary below about $13 \mathrm{~km}$ and reaches a value of near $1.9 \mathrm{~dB}$ under STD conditions (about $1.75 \mathrm{~dB}$ and close to $2 \mathrm{~dB}$ under SAW and TRO conditions; Schweitzer, 2010), due to its cross-sensitivity to $\mathrm{CH}_{4}$ (Table 2). The loss for $\mathrm{O}_{3}$ is very small above about $9 \mathrm{~km}$ to $12 \mathrm{~km}$ but becomes very significant below, due to the strong cross-sensitivity of the $\mathrm{O}_{3}$ channel pair to $\mathrm{H}_{2} \mathrm{O}$ (Table 2). This strong foreign species absorption also reduces the SNR of these channels which 

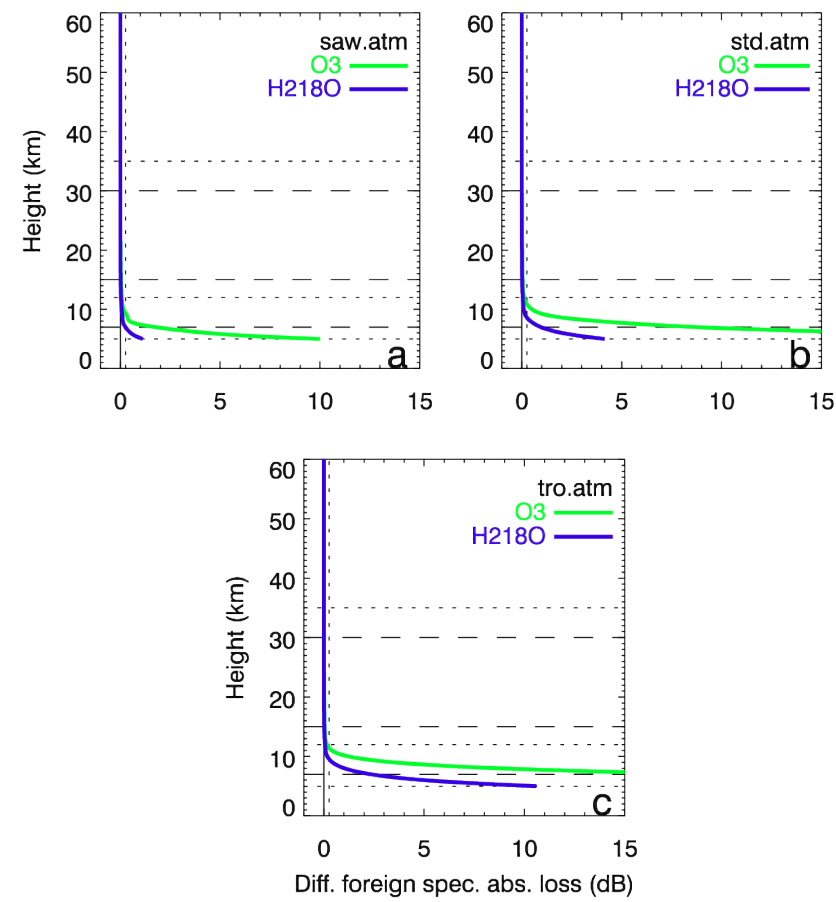

Fig. 6. Differential foreign species absorption loss for channel pairs with significant sensitivity of foreign species loss to atmospheric conditions. The losses are shown in the FASCODE SAW (a), STD (b), and TRO (c) atmospheres. The layout is the same as in Fig. 5.

is why in practice $\mathrm{O}_{3}$ cannot reasonably be retrieved below about $10 \mathrm{~km}$; highly accurate retrieval is possible above about $15 \mathrm{~km}$ which is the region of stratospheric ozone (Proschek et al., 2011a).

Overall we see that the differential foreign species absorption losses of most of the channel pairs are very small, with cross-sensitivities to foreign species being negligible in the stratosphere and generally still within $0.25 \mathrm{~dB}$ also at the UTLS bottom at $5 \mathrm{~km}$. This is also a result of the substantial effort put into a careful SWIR channel selection process to find an ensemble of channel pairs as optimal as possible (Schweitzer, 2010; Kirchengast and Schweitzer, 2011). The residual influence of foreign species can be modelled and effectively corrected for, enabling very accurate trace species retrievals (individual-profile VMR errors within $1 \%$ to $3 \%$ ), as discussed by Proschek et al. (2011a). For those species with substantial cross-sensitivities to $\mathrm{H}_{2} \mathrm{O}$ below $10 \mathrm{~km}, \mathrm{H}_{2}{ }^{18} \mathrm{O}$ and $\mathrm{O}_{3}$, the retrieval quality degrades in the upper troposphere, so that accurate $\mathrm{H}_{2}{ }^{18} \mathrm{O}$ profiles may be bottom-limited to above about $7 \mathrm{~km}$ and accurate $\mathrm{O}_{3}$ profiles to above about $10 \mathrm{~km}$, respectively.

\subsection{Influence of aerosol extinction}

Aerosols, suspended non- $\mathrm{H}_{2} \mathrm{O}$ particles in the atmosphere, can very effectively scatter and absorb radiation by Mie scattering/extinction (e.g. Salby, 1996; Liou, 2002). This results in some attenuation of LIO signals, though at the SWIR wavelengths of interest $>2 \mu \mathrm{m}$ the extinction is expected to be weak already since typical aerosol particle sizes are $<1 \mu \mathrm{m}$. The strength of the extinction depends on the concentration and size distribution of the aerosols. After major volcanic eruptions both concentration and sizes can significantly increase for a few months to about two years (Thomason and Peter, 2006; Thomason and Taha, 2003). Under non-volcanic conditions aerosol extinction of LIO signals in the UTLS will thus be weak, but under post-volcanic conditions it may increase.

We used the aerosol extinction model described in Sect. 2.2 to assess the magnitude of aerosol extinction of LIO signals, which is one potentially important background influence on top of defocusing (Sect. 3.2). Figure 7 shows the results from background aerosol load to post-volcanic load (top to bottom), both for the extinction loss in LIO channels directly (left column) and for the residual extinction loss in the differential transmission of channel pairs (right column). The selected channel pairs are representative of the SWIR range covered by LIO, from the low-wavelength end $\left(\mathrm{C}^{18} \mathrm{OO}\right)$ to the the high-wavelength end $\left(\mathrm{O}_{3}\right)$, with one pair $\left(\mathrm{CH}_{4}\right)$ mid-range. The spectral spacing of the absorption and reference channel is smallest for the $\mathrm{C}^{18} \mathrm{OO}$ channel pair and highest for the $\mathrm{CH}_{4}$ one (cf. Table 1).

As can be seen, the aerosol extinction loss as well as its signature in the differential transmission are very similar under background and medium aerosol load. The direct loss is small; it exceeds $0.25 \mathrm{~dB}$ only below about $8 \mathrm{~km}$ to $10 \mathrm{~km}$ and reaches a maximum of near $1 \mathrm{~dB}$ at $5 \mathrm{~km}$. Since the wavelength dependence of the aerosol loss is weak (linear only; see Eq. 3), the differential aerosol extinction loss stays negligible below $0.005 \mathrm{~dB}$ in all these non-volcanic conditions, including for the $\mathrm{CH}_{4}$ channel pair with largest channel spacing $(0.5 \%)$. The influence of volcanic aerosol on direct LIO transmissions, however, is estimated to be clearly observable and to increase quickly from about $25 \mathrm{~km}$ downwards until it remains at a level of about $2 \mathrm{~dB}$ to $3 \mathrm{~dB}$ below about $15 \mathrm{~km}$. The differential aerosol extinction loss can remain below $0.005 \mathrm{~dB}$ also in volcanic aerosol load, if the spectral spacing of absorption and reference channel is very small $(<0.1 \%)$, as for the $\mathrm{C}^{18} \mathrm{OO}$ channel pair. If the spectral separation is higher, residual influences of the aerosol extinction under volcanic load reach up to about $0.02 \mathrm{~dB}$ as seen for the $\mathrm{CH}_{4}$ channel pair that represents the largest spacing of LIO channel pairs of $0.5 \%$ (cf. Table 1).

Since the direct aerosol loss transgresses into the favourable signal range of $>0.25 \mathrm{~dB}$ below about $7 \mathrm{~km}$ to $22 \mathrm{~km}$ (depending on the aerosol load), it is possible to retrieve aerosol extinction loss and extinction coefficient profiles under such higher load conditions by a suitable algorithm (exploiting transmissions of reference channels, especially of the ones of the $\mathrm{CO}_{2}$ isotopes near $2.1 \mu \mathrm{m}$ which are both very clean from gas absorption and at the 

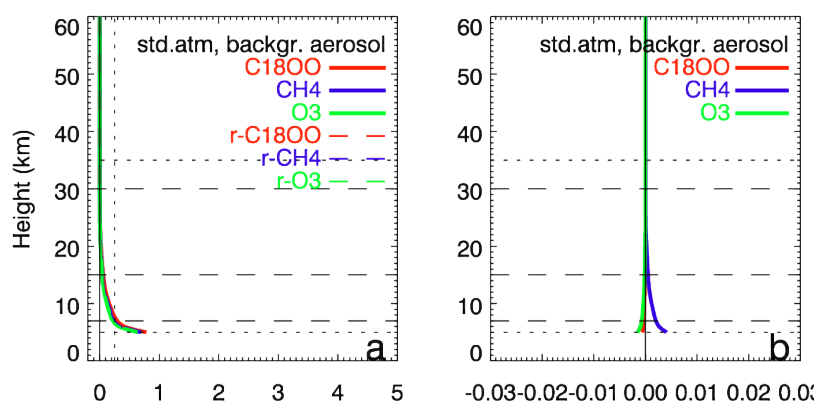

$-0.03-0.02-0.010 .000 .010 .020 .03$
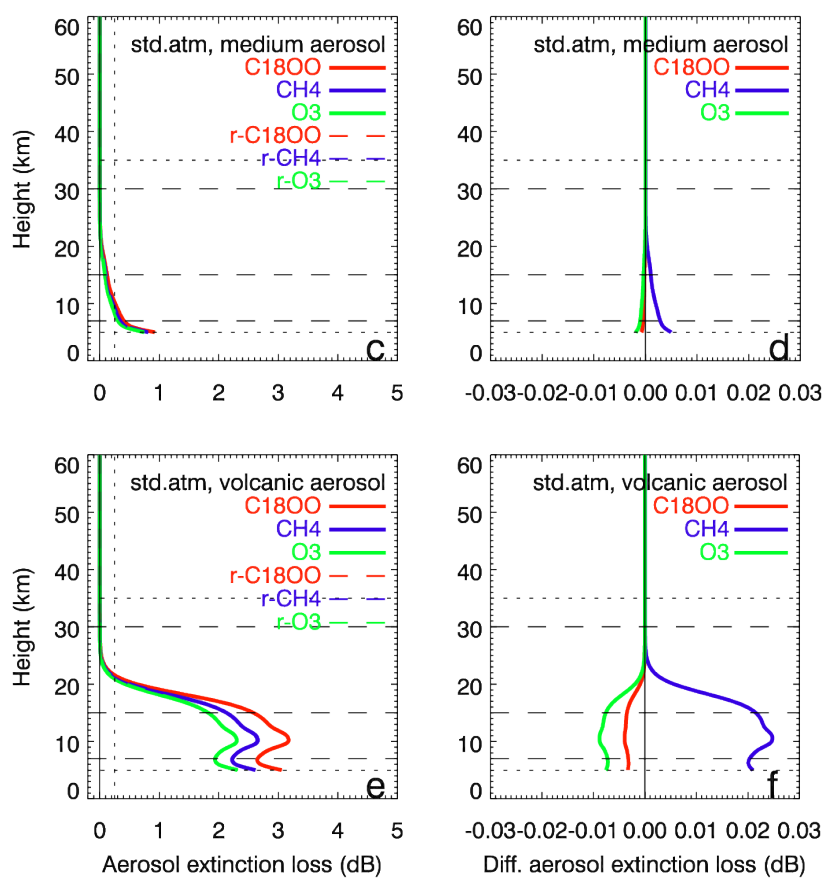

Fig. 7. Aerosol extinction loss (a, c, e) and differential aerosol extinction loss $(\mathbf{b}, \mathbf{d}, \mathbf{f})$ for three representative channel pairs with different spectral separation under FASCODE STD atmosphere conditions for background (a, b), medium (c, d), and volcanic (e, f) aerosol load. The vertical dotted line marks the boundary where the extinction loss, if transgressing it, enters into the favourable range for target species loss. The horizontal dotted and dashed lines mark target and threshold requirements, respectively, regarding the vertical range within which trace species shall be retrieved.

low-wavelength end with relatively best sensitivity to aerosol extinction). Any residual potentially bias-like influence on trace species retrieval that would be $>0.005 \mathrm{~dB}$ can then be corrected for based on the retrieved extinction loss profiles. Since we can reasonably expect an accuracy of at least about $20 \%$ of these retrieved profiles, residual losses of about $0.02 \mathrm{~dB}$ under volcanic load conditions for channels with largest spacing of $0.5 \%$ can thus be well corrected for to negligible residuals below $0.005 \mathrm{~dB}$. The degradation of overall SNR by up to about $3 \mathrm{~dB}$ under volcanic load will increase the statistical error in retrieved trace species profiles
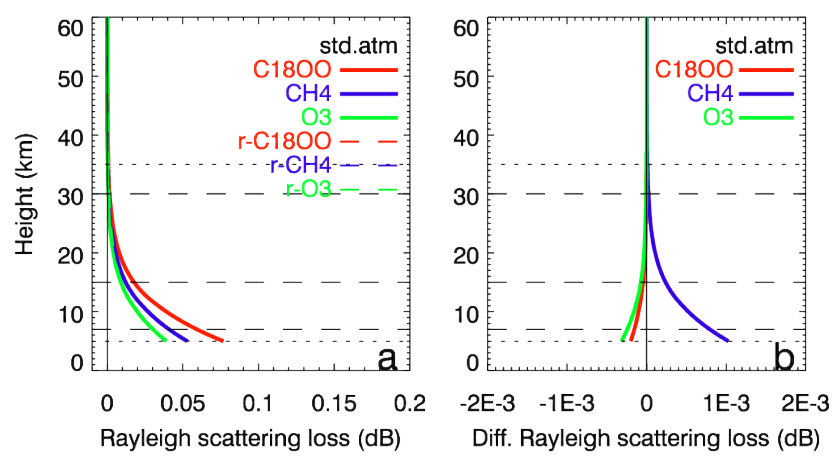

Fig. 8. Rayleigh scattering loss (a) and differential Rayleigh scattering loss (b) for three representative channel pairs with different spectral spacings, for FASCODE STD atmosphere conditions. The layout of the panels is the same as in Fig. 7 (the $\mathrm{x}$-axis ranges are smaller).

only in a minor way and have no impact on residual systematic error.

In summary the LIO technique is thus expected to deliver robust trace species retrieval of climate benchmarking quality also through episodes of volcanic aerosol load in the UTLS such as occurred in the post-Pinatubo years (1992/1993; Thomason and Peter, 2006). Given that we used an empirical model for scaling aerosol extinction coefficients measured near $1 \mu \mathrm{m}$ to the $2 \mu \mathrm{m}$ to $2.5 \mu \mathrm{m}$ range (see model description in Sect. 2.2), it will be useful to undertake further assessments of aerosol influence with potentially more sophisticated models in the future. From the construction of the Ångström coefficient in our model we estimate the results here are tentatively conservative; future more sophisticated estimates may find somewhat less aerosol influence.

\subsection{Influence of Rayleigh scattering}

The influence of Rayleigh scattering on LIO signals is shown in Fig. 8 both for direct-channel losses (left) and residual loss in differential transmissions (right). The same representative channel pairs are shown as used above for the aerosol extinction loss. Recall that Rayleigh scattering includes a $\lambda^{-4}$ dependence on wavelength (Eq. 4).

As can be seen, the losses due to Rayleigh scattering are very small. The direct loss increases with decreasing wavelength and reaches a maximum of about $0.04 \mathrm{~dB}$ to $0.08 \mathrm{~dB}$ at $5 \mathrm{~km}$. This is far below the $0.25 \mathrm{~dB}$ boundary. In the differential transmissions, the influence is further reduced to about $0.001 \mathrm{~dB}$ or below; the residual becomes smaller, the smaller the spectral spacing of channels is. Since Rayleigh scattering depends on air density and refractivity, which show at any height level fairly low variability globally, the behaviour under SAW and TRO conditions is closely the same as under the STD conditions shown. 
Overall it is very clear from these results that the influence of Rayleigh scattering loss on trace species retrieval from LIO signals is negligible at all heights under all atmospheric conditions.

\subsection{Total atmospheric loss and resulting intensity}

The sum of all atmospheric influences investigated above, the so-called total atmospheric loss of LIO signals, is illustrated in Fig. 9. As in Fig. 4 for target species absorption loss, the total losses are shown here under FASCODE STD atmosphere conditions for all 19 channels listed in Table 1. Regarding aerosol extinction, medium aerosol load was assumed.

The total atmospheric loss profiles reflect very well the different atmospheric influences and at the same time neatly show the total signal. The main part of the loss of absorption channels stems from the target species absorption as is desired. Defocusing loss yields also a significant contribution, especially below about $25 \mathrm{~km}$, and is the main loss in reference channels. The variability of the total atmospheric loss is mainly determined by the variability of the target species absorption loss and for some species partly also by the foreign species absorption loss. Hence, the absorption channels used to retrieve the $\mathrm{CO}_{2}$ isotopes, $\mathrm{CH}_{4}, \mathrm{~N}_{2} \mathrm{O}, \mathrm{O}_{3}$ and $\mathrm{CO}$ show very weak atmospheric variability, whereas the other channels show medium to strong variability under different atmospheric conditions, which is primarily caused by $\mathrm{H}_{2} \mathrm{O}$ variability (cf. Sect. 3.4); note that Schweitzer (2010) shows results regarding total atmospheric loss also for SAW and TRO conditions. The influence of the medium-load aerosol extinction is too small to be directly visible, the influence of Rayleigh scattering is negligible.

As discussed in Sect. 2.1, the total loss of the absorption channels should not exceed $21 \mathrm{~dB}$ (in compliancy with the ACCURATE mission design) to guarantee enough SNR of the LIO signals at the receiver. This requirement is evidently fulfilled by almost all channels under all atmospheric conditions in their designated height range (the $\mathrm{H}_{2} \mathrm{O}-1$ and $\mathrm{H}_{2} \mathrm{O}-2$ channels in Fig. 9a have the bottom-limit of their main range at $13 \mathrm{~km}$ and $8 \mathrm{~km}$, respectively, but are not needed below in retrievals; Proschek et al., 2011a). Therefore the respective target species can basically be retrieved within the whole UTLS region $(5 \mathrm{~km}$ to $35 \mathrm{~km})$, with bottom-limit constraints due to $\mathrm{H}_{2} \mathrm{O}$ cross-sensitivity below $10 \mathrm{~km}$ for $\mathrm{O}_{3}$ and $\mathrm{H}_{2}{ }^{18} \mathrm{O}$ (cf. Sect. 3.4; visible also in Fig. 9c and d), and top-limit constraints for the water isotopes $\mathrm{HDO}$ and $\mathrm{H}_{2}{ }^{18} \mathrm{O}$ for which sensitivity reaches up to about $12 \mathrm{~km}$ only (cf. Fig. 4).

Based on the total loss results, Fig. 10 finally depicts the behaviour of the LIO signal power reaching the receiver detectors (upper panel axes) and the receiver SNR (lower panel axes). The signal power is the actual observable of interest from which also retrieval processing in an end-to-end simulation framework will start (after in addition accounting for observation system/instrumental errors; see, e.g. Proschek
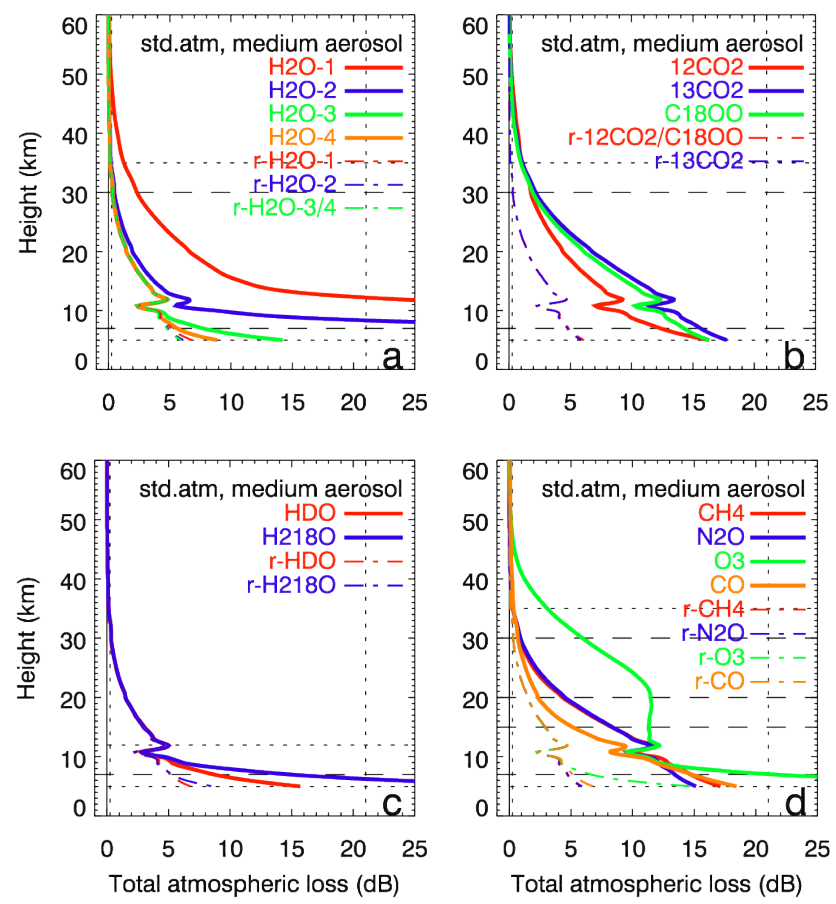

Fig. 9. Total atmospheric loss for the 13 absorption channels and the six reference channels listed in Table 1, for the FASCODE STD atmosphere and medium aerosol load. The layout of the panels is the same as in Fig. 4.

et al., 2011a, Figs. 4a and 5a therein). The received signal power is determined by subtracting the total atmospheric loss from the unattenuated top-of-atmosphere power reaching the receiver detectors, $P_{0}$, which is typically composed of the transmitted power minus all geometrical and instrumental losses caused by the observing system (e.g. propagation loss due to signal spreading, optical losses). The SNR at the receiver is then determined from the received signal power and the NEP of the detection system. Kirchengast et al. (2010) and Kirchengast and Schweitzer (2011) discuss these LIO link budget aspects in detail and show that for the ACCURATE system design a top-of-atmosphere power $P_{0}=-94 \mathrm{dBW}$ (for each individual received laser pulse signal with the signals being received at a $50 \mathrm{~Hz}$ basic sampling rate) and a top-of-atmosphere $\mathrm{SNR}_{0}=34 \mathrm{~dB}$ (at $2 \mathrm{~Hz}$ sampling rate corresponding to about $1 \mathrm{~km}$ to $2 \mathrm{~km}$ vertical resolution) are adequate baseline values.

We thus adopted these values for Fig. 10 here in order to discuss the results for the total atmospheric loss in terms of actual LIO observables, which is important to understand also the approach to mitigate the influence of some of the other atmospheric effects discussed below. From the $P_{0}$ and $\mathrm{SNR}_{0}$ values we see that the unattenuated LIO laser pulse signal power detected is about $400 \mathrm{pW}$ and that the associated signal-to-noise ratio is about 500 at the basic $50 \mathrm{~Hz}$ sampling rate (2500 at a $2 \mathrm{~Hz}$ sampling rate). This implies 

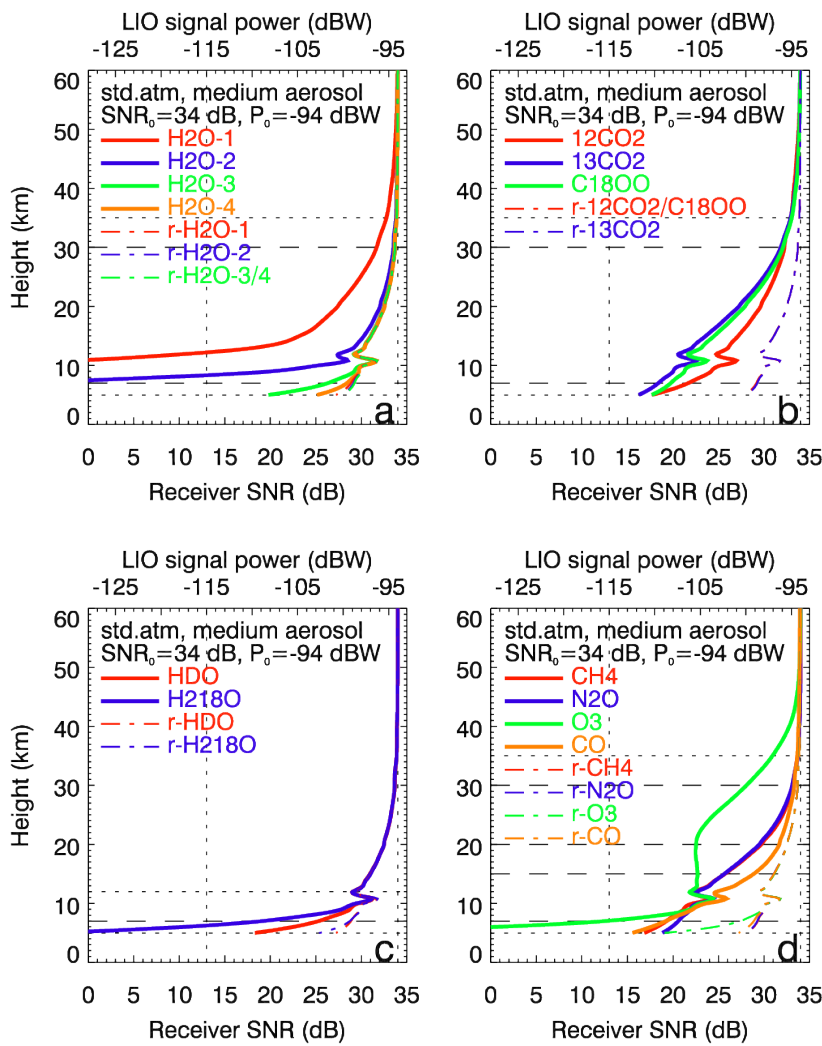

Fig. 10. Received signal power (upper axes) and receiver SNR (lower axes) for the channels listed in Table 1 on the basis of adopting a top-of-atmosphere power of $-94 \mathrm{dBW}$ and a corresponding SNR of $34 \mathrm{~dB}$, both being baseline values of the ACCURATE mission design. The results are shown for the FASCODE STD atmosphere and medium aerosol load. The layout of the panels is the same as in Fig. 4.

a detector noise level of only about $0.8 \mathrm{pW}$, providing even individual pulse signals at high SNR. In order to keep good basic accuracy, signal power should not fall below a few $\mathrm{pW}$ (say $3 \mathrm{pW}$, or $-115 \mathrm{dBW}$, or $6 \mathrm{~dB}$ raw SNR) even if all atmospheric loss effects are in action below $10 \mathrm{~km}$. This implies that the effective SNR at $2 \mathrm{~Hz}$ sampling rate, reflecting the final resolution for use of the data, should not fall below $13 \mathrm{~dB}$ as discussed in Sect. 2.1 and as marked in Fig. 10. As can be seen in Fig. 10, all channels selected fall into the favourable range (with the upper-troposphere limitations for $\mathrm{O}_{3}$ and the $\mathrm{H}_{2} \mathrm{O}$ isotopes discussed above and visible in panels $\mathrm{c}$ and d).

Therefore, if the LIO technique is implemented to meet at least the specifications of the ACCURATE system design baselined here, the available SNR provides enough sensitivity to enable retrieval of the ten target trace species with high accuracy under all atmospheric conditions. In order to learn which level of retrieval performance can be achieved, Proschek et al. (2011a) started with LIO observables of the quality as discussed here. They found individual-profile retrieval errors within $1 \%$ to $3 \%$ and that the retrieved profiles are obtained essentially without biases. Kirchengast and Schweitzer (2011) estimated this performance already before using a simplified estimation process. See those studies for details.

\subsection{Comments on further atmospheric effects}

\subsubsection{Clouds}

Clouds affect the intensity of received LIO signals in two ways. On the one hand, their SWIR extinction coefficients are high, leading to strong cloud extinction loss which fully blocks the signals except for very thin or small (cirrus) clouds. On the other hand, clouds may scatter solar radiation towards the receiver, leading to an amplification of the detected signal, but this effect is very small (about 0.5 to $3.5 \mathrm{~mW} \mathrm{~m}^{-2} \mathrm{~nm}^{-1} \mathrm{sr}^{-1}$; Emde and Proschek, 2010); see the separate comments on scattered solar radiation below.

For liquid water clouds, the cloud extinction can be described by the Mie theory, since the microphysical properties of water clouds (like water content, size and shape of droplets) are not difficult to describe (Hu and Stamnes, 1993). The extinction due to ice water clouds is more complicated, since ice particles can have many different sizes and shapes, which is why various parametrisations exist to describe their extinction coefficients and other optical properties (e.g. Key et al., 2002).

Investigations by Emde and Proschek (2010) showed that typical liquid water clouds induce a loss of much more than $30 \mathrm{~dB}$ in LIO intensities, which effectively corresponds to a full blocking of signals (see the requirements for adequate SNR in Sect. 3.7 above). Also ice water clouds are usually not transparent, except for very thin cirrus clouds with an ice water content at the $0.001 \mathrm{~g} \mathrm{~m}^{-3}$ level (assuming an alongpath extension of several $10 \mathrm{~km}$ ). They induce an extinction loss of up to about $10 \mathrm{~dB}$ and hence still allow to retrieve trace species through the clouds under degraded SNR. Details of these studies will be published elsewhere.

For the common cases in which clouds will block the LIO signals, the LMIO technique by design has the LMO signals continuing to track through clouds (so as to retrieve the thermodynamic variables through clouds) and also has the reception sequence of LIO signals continuing to work independent of clouds interfering in propagation paths of individual laser pulse signals. This is because the LIO receiver telescope has accurate pointing independent of received signal; the received LIO signal power will simply fall back to background levels for those pulse signals that have been blocked by cloud extinction. This also implies that the blocking of individual pulses does not affect the quality of pulses before and after so that any LIO pulse signal is received basically at clear-air quality if it somehow found a "hole" in intermittent cloudiness (note that the Fresnel diameter of the SWIR laser signals is about $3 \mathrm{~m}$ only so that the received power of individual pulse signals propagates along highly confined 
propagation "tubes"; Kirchengast and Schweitzer, 2011). In this way, high-quality target species transmission values can be retrieved, with gaps, across layered cloudiness, where profiles of cloud layering are a byproduct flagging the gaps. Interpolating over limited gaps then allows trace species retrieval of still high quality. An overview of cloudy air retrieval, the developments of which are currently on-going, is provided by Proschek et al. (2011b).

The influence of clouds on the tropospheric penetration of atmospheric profiles retrieved from LIO was so far roughly estimated, as a worst case limit, from analysing solar occultation data of the Canadian Atmospheric Chemistry Experiment (ACE) satellite (Harrison and Bernath, 2010; including G. C. Toon, Jet Propulsion Lab., CA, USA, personal communication, 2009). These data show that about $40 \%$ of all measured profiles reach down to about $7.5 \mathrm{~km}, 20 \%$ reach even down to about $5 \mathrm{~km}$. Exception is a tropical band within $15^{\circ}$ of the equator, where only $20 \%$ of the profiles reach down to about $7.5 \mathrm{~km}$. It is expected that LIO data have an improved vertical coverage into the upper troposphere due to their capability to penetrate intermittent cloudiness as outlined above.

\subsubsection{Turbulence}

Atmospheric turbulence is associated with random variations of the refractive index, which in turn affect optical beams. This occurs because the intensity of a beam is multiply diffracted on small-scale air density irregularities. One relevant effect is intensity fluctuations of the beam, also called scintillation, which is caused by random redistribution of the energy within the cross section of the beam, another one additional spreading of the beam (in addition to the spreading caused by the pure refraction).

First estimations by Sofieva (2009) and Horwath and Perlot (2008), details of which will be published elsewhere, show that the influence of scintillation on single LIO channels is rather high, as is for example known from stellar occultation data like the GOMOS instrument on Envisat (Kyrölä et al., 2004). In particular, the relative intensity fluctuations rapidly grow with decreasing altitude, nearly proportional to air density, from about 0.05 (r.m.s.) near $30 \mathrm{~km}$ up to the saturation level of about 1 (r.m.s.) below about $20 \mathrm{~km}$. This saturation level depends on the strength of the refractive index fluctuations, the atmospheric path length, and the wavelength of the signal (e.g. Andrews and Phillips, 2005).

Fortunately the correlation of the scintillations at closely spaced frequencies is very high since spectrally adjacent channels essentially avoid dispersive effects and therefore signals pass through the same air density irregularities. The adverse influence of scintillation can thus be largely removed by application of the differential transmission retrieval approach with sufficiently closely spaced channels. Sofieva (2009) recommends a frequency separation of a channel pair of up to $0.5 \%$ only, which could be realised in the
ACCURATE design by careful channel selection (Table 1). This strict closeness is required because the relative error in the differential transmission rapidly grows with increasing wavelength separation, due to the slight chromatic shift of the signal path of the absorption relative to the reference channel, since the infrared refractivity is still slightly dispersive at $>2 \mu \mathrm{m}$ (Sect. 2.2, Eq. 1). For example, at a $50 \mathrm{~Hz}$ sampling rate the residual scintillation error in the differential transmission for channels near $2.1 \mu \mathrm{m}$ with a separation of $0.1 \%$ was estimated to be at an acceptable level of only about $1 \%$ to $1.5 \%$ near $10 \mathrm{~km}$ and about $1.5 \%$ to $2.5 \%$ near $5 \mathrm{~km}$, while at a separation of $1 \%$ it would already be about 10 times as large. This error is a statistical error with negligible bias component. Most of the channel pairs of the ACCURATE design have a spectral separation of less than $0.1 \%$ to $0.25 \%$, the largest separations are $0.5 \%$ (Table 1); the latter implying about five times the error of $0.1 \%$ separation.

The residual scintillation error can be mitigated further by a factor of 5 or more if the slight chromatic shift between the ray paths of the channels is compensated for based on a slight time shift of transmitting the absorption channel pulses relative to the reference channel pulses, to ensure close alignment of the ray paths and thus higher correlation of the scintillations (Sofieva, 2009). This can be implemented using knowledge on the atmospheric refraction profile during occultation events, where the required $20 \%$ accuracy is readily achievable (or outperformed) in the UTLS (Kirchengast et al., 2010). The chromatic shift compensation is estimated to effectively reduce the residual error for channels spaced by $0.5 \%$ to at least the error level of channels spaced by $0.1 \%$ only.

\subsubsection{Wind}

Wind sets air molecules in motion, which is why they are moved towards or away from the transmitter. Hence the frequency seen by the molecules differs slightly from the one being transmitted, according to the Doppler effect. The molecules thus absorb this slightly shifted frequency. Since absorption lines in the SWIR spectrum are very narrow, this shift is visible for absorption channels in form of slight transmission changes.

Practically the effect is very small when considering the centre of absorption lines, which is why the influence of wind needs only be very roughly accounted for when working with line centres as done for trace species retrieval. Typical meridional winds, the winds dominating for polar or near-polar LEO-LEO configurations, have speeds of less than $30 \mathrm{~m} \mathrm{~s}^{-1}$. This leads to a relative frequency shift of about $10^{-7}$. As a representative example, such a line-of-sight wind speed would in case of the $\mathrm{C}^{18} \mathrm{OO}$ line lead to a reduction of the transmission by about $0.03 \mathrm{~dB}$ at $10 \mathrm{~km}$ and $0.01 \mathrm{~dB}$ at $30 \mathrm{~km}$, relative to the centre of the line probed in case of zero wind speed. Background knowledge of the wind speed with about 
$10 \mathrm{~m} \mathrm{~s}^{-1}$ uncertainty (available, e.g. from atmospheric analyses or short-range forecasts) is thus estimated to be sufficient to enable accurate trace species retrieval with systematic error residuals below $0.005 \mathrm{~dB}$.

The effect is about 10 times larger when considering the inflection points of an absorption line where the spectral gradient of transmission is strongest. Using dedicated LIO signals at such inflection points of a highly symmetric absorption line, which is at the same time stable under different atmospheric conditions, can thus be used to retrieve the line-of-sight wind speed (Kirchengast and Schweitzer, 2011). This capability is an integral part of the ACCURATE concept (Kirchengast et al., 2010). In essence, it is the differential transmission between the two inflection points that is exploited, where the $\mathrm{C}^{18} \mathrm{OO}$ line turned out as a particularly suitable line (Schweitzer, 2010; Kirchengast and Schweitzer, 2011). The retrieved 1.o.s. wind speed profile can then be used to correct the small off-centre Doppler shifts in the trace species retrieval discussed above, eliminating the need for background knowledge of wind speed from an external atmospheric field. More details on the LIO wind capability can be found in Schweitzer (2010).

\subsubsection{Scattered solar radiation}

Solar radiation can be scattered into the receiver telescope either by Rayleigh scattering due to clear air or by particle (Mie-type) scattering due to clouds. Since the SWIR range of interest ( $2 \mu \mathrm{m}$ to $2.5 \mu \mathrm{m})$ is intentionally located as far as possible in the long-wavelength tail of the solar Planck radiation spectrum, the intensity is already low (see, e.g. Liou, 2002) and scattering influences are thus to be expected very small. Aerosol-scattered solar radiation is expected to be negligible since concentrations are too small and wavelengths too long.

From error budget analyses we estimated that the Rayleigh-scattered solar radiation captured by the telescope during any single pulse measurement is, for the ACCURATE design described by Kirchengast et al. (2010), below the receiver noise level (about $0.8 \mathrm{pW}$; cf. Sect. 3.7) and thus negligible. This holds over the whole UTLS also during all conditions of bright day; it reaches the $0.1 \mathrm{pW}$ level but stays below $0.5 \mathrm{pW}$ also at the UTLS bottom near $5 \mathrm{~km}$ for the shortest relevant wavelengths near $2.1 \mu \mathrm{m}$. Details will be published elsewhere. We note for completeness that also scattering (or other radiation) from surface sources is negligible, since the telescope will observe downwards to minimum tangent altitudes of $2.5 \mathrm{~km}$ only where no surface radiation can enter the field of view (FOV) of the telescope. Likewise, in the case of direct sun, a geometrical situation which rarely occurs when using near-polar orbiting satellites as in the ACCURATE concept, the receiver will be shielded from this strong signal to protect the instruments. This will ensure that indeed only scattered solar radiation can enter the telescope.
Other than for Rayleigh scattering, cloud-scattered solar radiation is estimated to be observable under certain conditions (Kirchengast et al., 2010; Emde and Proschek, 2010). Relevant influence can arise in particular from clouds fractionally covering the FOV of the telescope, e.g. from cloud edges near cloud top or bottom (if there is full cloud blocking of the LIO signal, the influence will not be relevant). During bright day, this scattering could sometimes exceed the detector noise level of about $0.8 \mathrm{pW}$, but is estimated to stay within about a factor of ten of this level. Such an influence is still small given a basic signal strength at the $100 \mathrm{pW}$ level (cf. Sect. 3.7). Moreover, it is foreseen to be rigorously controlled, and as necessary corrected for, by a receiver design including a close time spacing of interleaved laser-pulse and background signals within $5 \mathrm{~ms}$ (Kirchengast et al., 2010).

Briefly, this design includes that before and after each laser pulse signal measurement also a background measurement is performed within $\pm 2.5 \mathrm{~ms}$. This corresponds to a vertical shift of within $\pm 5 \mathrm{~m}$, given typical vertical scan velocities of the occultation events of about $2 \mathrm{~km} \mathrm{~s}^{-1}$ (Kirchengast et al., 2010). Such a shift is small enough so that the receiver telescope with a FOV of about $3 \mathrm{~km}$ vertical extend at atmospheric tangent point sees essentially the same scattering scene both for the pulse and background measurement. The background measurement thus enables rigorous control of the SNR of each single received pulse, for optimal quality independent of whether scattered radiation is available above receiver noise level or not. The background measurement is furthermore planned at multiple detection pixels adjacent to the pulse measurement. Thus, in case the background power is needed to be subtracted, an average can be subtracted which only insignificantly increases the noise in the background-corrected pulse signal. Also on this topic of cloud scattering details will be published elsewhere.

\subsubsection{Terrestrial thermal radiation}

The SWIR spectral range is located at the short-wavelength side of the Planck spectrum of Earth's thermal radiation (e.g. Liou, 2002). Since these short wavelengths see an exponential falloff of the thermal radiation spectrum with its maximum near $10 \mu \mathrm{m}$, the radiation at $<2.5 \mu \mathrm{m}$ is already very small. We estimated its influence by means of worst case values of the thermal radiation entering the receiver telescope, where we used a temperature of $280 \mathrm{~K}$, because UTLS temperatures are typically below, and an upper-end wavelength of $2.5 \mu \mathrm{m}$. The estimated power turns out to be always at most near $0.01 \mathrm{pW}$, which is far below receiver noise level $(0.8 \mathrm{pW})$. Hence, terrestrial thermal radiation is negligible in a mission design like ACCURATE. 


\section{Summary and conclusions}

In this study we discussed atmospheric influences on SWIR laser signals which are transmitted between two LEO satellites in occultation geometry. Such an occultation system is called LIO and primarily aims at providing accurate profiles of atmospheric trace species, especially of greenhouse gases, and of l.o.s. wind speed. Other retrieval products can be profiles of cloud layering, aerosol extinction coefficient, and turbulence strength. LIO is part of the LMIO method (Kirchengast and Schweitzer, 2011), where the above profiles are determined in synergy and consistent with thermodynamic profiles (pressure, temperature, humidity) from LMO signals. A detailed mission concept for implementing the LMIO method, the ACCURATE mission proposed by Kirchengast et al. (2010), was used as baseline mission design for this study.

Quasi-realistic propagation simulations with the EGOPS/xEGOPS simulation system (Fritzer et al., 2010a,b) have been used to investigate the atmospheric influences on LIO signals and their implications for the total received LIO signal power. Most of the influences (defocusing, target species absorption, foreign species absorption, aerosol extinction, Rayleigh scattering as well as their sum) have been assessed by means of simulation results for the set of 19 SWIR channels that was the basis for the ACCURATE mission design. The influence of refractivity was considered in view of its different effect on MW and SWIR ray paths, resulting in slightly different ray bending and thus tangent point heights of LIO and LMO signals. Further atmospheric effects (the influence of clouds, turbulence, wind, scattered solar radiation and atmospheric thermal radiation) were discussed in an introductory manner, referring to several recent scientific-technical reports; detail results to these ends will be published elsewhere.

We established that the set of SWIR channels of the ACCURATE mission provides very good sensitivity to target species absorption. In particular, eight species $\left(\mathrm{H}_{2} \mathrm{O}, \mathrm{CO}_{2}\right.$, ${ }^{13} \mathrm{CO}_{2}, \mathrm{C}^{18} \mathrm{OO}, \mathrm{CH}_{4}, \mathrm{~N}_{2} \mathrm{O}, \mathrm{O}_{3}, \mathrm{CO}$ ) can be acquired within the whole UTLS region under all atmospheric conditions, except for lower-limit constraints for $\mathrm{O}_{3}$ the signal of which can become obscured below $10 \mathrm{~km}$. For two further species, $\mathrm{HDO}$ and $\mathrm{H}_{2}{ }^{18} \mathrm{O}$, which have a very low concentration in the atmosphere (especially in the stratosphere), sensitivity is available within about $5 \mathrm{~km}$ to $12 \mathrm{~km}$ only.

The cross-sensitivity of most of the channels to the absorption by foreign species is favourably small; the influence of foreign species even falls below $0.25 \mathrm{~dB}$ down to $5 \mathrm{~km}$ for most of the channel pairs when considering the differential transmissions. Exceptions are the channel pairs used for the retrieval of $\mathrm{CO}, \mathrm{O}_{3}$, and $\mathrm{H}_{2}{ }^{18} \mathrm{O}$. For $\mathrm{CO}$, the influence does reach near $2 \mathrm{~dB}$ in the differential transmission but is stable, which is why it can be robustly corrected for in the retrieval as part of the foreign species correction (see Proschek et al., 2011a). The $\mathrm{O}_{3}$ channels are substantially affected by foreign species absorption due to $\mathrm{H}_{2} \mathrm{O}$ below about $10 \mathrm{~km}$, wherefore the retrieval of $\mathrm{O}_{3}$ is limited to heights above. Also the $\mathrm{H}_{2}{ }^{18} \mathrm{O}$ intensity is significantly affected by $\mathrm{H}_{2} \mathrm{O}$ absorption below about $7 \mathrm{~km}$, which as well reduces the retrieval range for this species under moist conditions.

The aerosol extinction loss can transgress the limit of $0.25 \mathrm{~dB}$ into the favourable signal range of target species absorption loss below about $7 \mathrm{~km}$ to $22 \mathrm{~km}$, depending on the aerosol load. In this case it is possible to retrieve aerosol extinction by a suitable algorithm. In the differential transmission, aerosol influence is significantly reduced and essentially negligible in its influence for trace species retrieval. Only under volcanic aerosol load at post-Pinatubo levels a small influence can remain (estimated to reach about $0.02 \mathrm{~dB}$ ), which can be corrected for in this case by use of the retrieved aerosol extinction profiles.

Defocusing loss has a significant influence on the signal intensity and reduces it by up to about $5 \mathrm{~dB}$ near $5 \mathrm{~km}$, which is to be taken into account in the power budget of the intersatellite link in order to ensure sufficient SNR of received signal power in the upper troposphere. The direct effect of defocusing on the trace species retrieval is negligible, however, since due to its negligible frequency dependence it is eliminated in the differential transmission. The influence of Rayleigh scattering is negligible in both direct and differential transmission signals.

The difference in the MW and SWIR refractivities leads to different tangent point heights of LIO and LMO ray paths, with the degree of tangent point separation determined by the presence of water vapour. Around $5 \mathrm{~km}$, where moisture is strongest, the difference is about $0.15 \mathrm{~km}$ in SAW conditions, $0.5 \mathrm{~km}$ in STD and $1 \mathrm{~km}$ in TRO conditions. Following the decrease of water vapour, it strongly decreases with increasing altitude and becomes negligible from about $9 \mathrm{~km}$ to $13 \mathrm{~km}$ upwards. It is thus important in the trace species retrieval to compute correct LIO height levels in the upper troposphere, supported by LMO information (Proschek et al., 2011a).

Clouds generally block SWIR signals, except for very thin or small (cirrus) clouds, which attenuate the signal significantly but not completely (Emde and Proschek, 2010). This blocking or partial extinction is addressed in the ACCURATE mission concept by a design allowing retrieval of a cloud layering profile from reference signals and its use in trace species retrieval when scanning through intermittent upper tropospheric cloudiness. Since LIO is used in combination with LMO, accurate height levelling can be maintained through clouds, which is why also top and bottom heights of (layered) cloudiness can be determined, and atmospheric variables at these top and bottom heights.

Atmospheric turbulence induces major intensity fluctuations of the LIO signals, also called scintillations. Favourably, these fluctuations are highly correlated when considering closely spaced frequencies; close spacing of absorption and reference signals within $0.5 \%$ is thus part of the 
ACCURATE design, combined with compensation of chromatic shift of ray paths between the channels (Sofieva, 2009). In this way, the influence of residual scintillation noise becomes small, comparable to receiver thermal noise, in the differential transmission.

Wind along ray paths causes air to move and induces absorption at slightly shifted wavelengths due to Doppler shift. By using the centre of absorption lines for the trace species retrieval, this change in transmission is very small and hence can be corrected for by a moderately accurate (to about $10 \mathrm{~m} \mathrm{~s}^{-1}$ ) background wind profile. However, the influence becomes useful as an observable when regarding the inflection points of a highly symmetric absorption line. This is the basis for line-of-sight wind retrieval, effectively from the differential transmission between the inflection points (Schweitzer, 2010; Kirchengast and Schweitzer, 2011). Using these retrieved wind profiles also eliminates the need for background wind profiles supporting the trace species retrieval.

In principle, the received signal power could also be increased due to atmospheric influences, namely by solarscattered radiation and terrestrial thermal radiation collected within the FOV of the receiver telescope. We find these influences generally negligible, however, since the chosen SWIR range is intentionally located in the "hole" between the solar Planck spectrum and the terrestrial Planck spectrum. Cloudscattered solar radiation is the only process found to potentially provide signal above receiver noise level. This is addressed in the ACCURATE design by a close time spacing of interleaved laser-pulse and background signals within $5 \mathrm{~ms}$, which enables to correct for such radiation while only insignificantly increasing received signal noise.

Putting the total atmospheric loss into context with the ACCURATE design of top-of-atmosphere received power and SNR (baseline $-94 \mathrm{dBW}$ and $34 \mathrm{dBHz}$; Kirchengast et al., 2010), we found the available LIO signal level throughout the atmosphere down to $5 \mathrm{~km}$ adequate for enabling accurate trace species retrieval. Overall we find the set of LIO channels, and the ACCURATE design for implementing the full LMIO method, to be a new observing system of high promise for measuring greenhouse gas profiles, and other atmospheric variables, with unprecedented quality over the UTLS. First retrieval performance analysis results based on a realistic retrieval processing chain and end-to-end simulations underpin this promise (Proschek et al., 2011a).

In future work we intend to advance the simulation capabilities of the EGOPS/xEGOPS system and the assessment of atmospheric influences on LIO signals by broader variability of atmospheric trace gas fields (atmospheric analysis fields complemented by composition analysis fields) and also by employing the capabilities for cloud, wind, and turbulence modelling, including in ensemble-based statistical analyses. This will allow to consolidate this first assessment by a statistical analysis that can also be linked to an ensemble-based retrieval performance analysis. As a specific issue, we consider to investigate the region within $1.9 \mu \mathrm{m}$ and $2 \mu \mathrm{m}$ for absorption lines sensitive to the water isotopes $\mathrm{HDO}$ and $\mathrm{H}_{2}{ }^{18} \mathrm{O}$, attempting to increase the vertical range of sensitivity for these species so that they may become useful for troposphere/stratosphere exchange studies. Finally, a ground-based LIO experiment was recently conducted, for a $144 \mathrm{~km}$ link at about $2.4 \mathrm{~km}$ height between observatories at the Canary Islands (by Univ. of York, Univ. of Graz, and Univ. of Manchester, P. F. Bernath et al., 2011), which we use to learn about atmospheric influences based on real data somewhat similar to a LEO-LEO link.

Acknowledgements. We thank J. Fritzer, F. Ladstädter, and M. Pock for contributions to EGOPS and xEGOPS developments. EGOPS was developed by an international consortium led by UniGraz (AT), involving partners at Danish Meteorol. Inst. (DK), Obukhov Inst. of Atmos. Physics (RU), Chalmers Univ. of Technology (SE), Univ. of Bremen (DE), Met. Office (UK), Terma Elektronik A/S (DK) and RUAG Space GmbH (AT). xEGOPS was developed by UniGraz (AT), with contributions by E. Martini (Univ. of Siena, IT), V. Sofieva (Finnish Meteorol. Inst., FI) and C. Emde (Univ. of Munich, DE). Funds for the EGOPS/xEGOPS development were provided by ESA/ESTEC (NL), FWF and FFG-ALR (AT), and EUMETSAT/HQ (DE). RFM including the FASCODE atmospheres was provided by A. Dudhia (Univ. of Oxford, UK), HITRAN by L. Rothman (Harvard Univ., USA). This study was funded by FFG-ALR (AT) under the ASAP projects ACCURAID, EOPSCLIM and ACCU-Clouds, and by ESA/ESTEC (NL) under the GSP-ACTLIMB and STSE-IRDAS studies.

Edited by: K. B. Lauritsen

\section{References}

Anderson, G. P., Clough, S. A., Kneizys, F. X., Chetwynd, J. H., and Shettle, E. P.: AFGL Atmospheric Constituent Profiles (0-120 km), Environm. Res. Papers 954, AFGL-TR-86-0110, Optical Physics Division, Air Force Geophysics Laboratory, Hanscom AFB, Massachusetts, USA, 1986.

Andrews, L. C. and Phillips, R. L.: Laser beam propagation through random media, 2nd Edn., SPIE Press, Bellingham, Washington, USA, 2005.

Anthes, R. A., Bernhardt, P. A., Chen, Y., Cucurull, L., Dymond, K. F., Ector, D., Healy, S. B., Ho, S.-P., Hunt, D. C., Kuo, Y.H., Liu, H., Manning, K., McCormick, C., Meehan, T. K., Randel, W. J., Rocken, C., Schreiner, W. S., Sokolovskiy, S. V., Syndergaard, S., Thompson, D. C., Trenberth, K. E., Wee, T.K., Yen, N. L., and Zhang, Z.: The COSMIC/FORMOSAT3 mission: early results, B. Am. Meteorol. Soc., 89, 313-333, doi:10.1175/BAMS-89-3-313, 2008.

Bönsch, G. and Potulski, E.: Measurement of the refractive index of air and comparison with modified Edlén's formulae, Metrologia, 35, 133-139, doi:10.1088/0026-1394/35/2/8, 1998.

Cardinali, C.: Forecast sensitivity to observation (FSO) as a diagnostic tool, Tech. Memorandum 599, European Centre for Medium-Range Weather Forecasts, Reading, UK, 2009.

Edlén, B.: The refractive index of air, Metrologia, 2, 71-80, doi:10.1088/0026-1394/2/2/002, 1966. 
Edwards, D. P.: High level algorithm definition document (RFM), Tech. Rep. for ESA/ESTEC PO-TN-OXF-GS-0004, Institute of Atmospheric, Oceanic and Planetary Physics, Univ. of Oxford, Oxford, UK, 1996.

Emde, C. and Proschek, V.: Atmospheric impacts on ILO signals: Impact of cloud scattering, Tech. Rep. for ESA-ESTEC Technical Note 2 - Part of the TR-IRPERF Report, Deutsches Zentrum für Luft- und Raumfahrt, Wessling, Germany, 2010.

Feng, D. D., Syndergaard, S., Herman, B. M., Kursinski, E. R., Yunck, T. P., and Romberg, F. W.: Deriving atmospheric water vapour and ozone profiles from active microwave occultation measurements, in: Sensors, Systems and Next-Generation Satellites IV, edited by: Fujisada, H., Lurie, J. B., Ropertz, A., and Weber, K., vol. 4169 of SPIE Proceedings Series, SPIE - Int. Soc. Optical Engineering, Bellingham, USA, 299-308, dpo:10.1117/12.417135, 2000.

Fritzer, J. M., Kirchengast, G., Pock, M., and Proschek, V.: End-toEnd Generic Occultation Performance Simulation and Processing System version 5.5 - Detailed Design Document, Tech. Rep. for ESA-ESTEC No. 2/2010, Wegener Center and Inst. for Geophys., Astrophys., and Meteorol., Univ. of Graz, Graz, Austria, 2010a.

Fritzer, J. M., Kirchengast, G., Pock, M., and Proschek, V.: Endto-End Generic Occultation Performance Simulation and Processing System version 5.5 - Software User Manual, Tech. Rep. for ESA-ESTEC No. 1/2010, Wegener Center and Inst. for Geophys., Astrophys., and Meteorol., Univ. of Graz, Graz, Austria, 2010b.

Gobiet, A., Foelsche, U., Steiner, A. K., Borsche, M., Kirchengast, G., and Wickert, J.: Climatological validation of stratospheric temperatures in ECMWF operational analyses with CHAMP radio occultation data, Geophys. Res. Lett., 32, L12806, doi:10.1029/2005GL022617, 2005.

Gorbunov, M. E. and Kirchengast, G.: Processing X/K band radio occultation data in the presence of turbulence, Radio Sci., 40, RS6001, doi:10.1029/2005RS003263, 2005.

Gorbunov, M. E. and Kirchengast, G.: Fluctuations of radio occultation signals in $\mathrm{X} / \mathrm{K}$ band in the presence of anisotropic turbulence and differential transmission retrieval performance, Radio Sci., 42, RS4025, doi:10.1029/2006RS003544, 2007.

Hajj, G. A., Kursinski, E. R., Romans, L. J., Bertiger, W. I., and Leroy, S. S.: A technical description of atmospheric sounding by GPS occultation, J. Atmos. Sol.-Terr. Phy., 64, 451-469, doi:10.1016/S1364-6826(01)00114-6, 2002.

Harrison, J. J. and Bernath, P. F.: Spectroscopic properties of greenhouse gases from 2.0 to $2.5 \mu \mathrm{m}$, Tech. Rep. UoY/ESAIRDAS/Greenhouse/January 2010, Dept. of Chemistry, Univ. of York, York, UK, 2010.

Healy, S. B.: Refractivity coefficients used in the assimilation of GPS radio occultation measurements, J. Geophys. Res., 116, D01106, doi:10.1029/2010JD014013, 2011.

Healy, S. B. and Thépaut, J.-N.: Assimilation experiments with CHAMP GPS radio occultation measurements, Q. J. Roy. Meteorol. Soc., 132, 605-623, doi:10.1256/qj.04.182, 2006.

Herman, B., Feng, D., Flittner, D., Kursinski, E. R., Syndergaard, S., and Ward, D.: An overview of the University of Arizona ATOMS project, in: Occultations for Probing Atmosphere and Climate, edited by: Kirchengast, G., Foelsche, U., and Steiner, A. K., Springer, Berlin, Heidelberg, Germany, 189-200, 2004.
Ho, S.-P., Kirchengast, G., Leroy, S., Wickert, J., Mannucci, A. J., Steiner, A. K., Hunt, D., Schreiner, W., Sokolovskiy, S., Ao, C., Borsche, M., von Engeln, A., Foelsche, U., Heise, S., Iijima, B., Kuo, Y.-H., Kursinski, R., Pirscher, B., Ringer, M., Rocken, C., and Schmidt, T.: Estimating the uncertainty of using GPS radio occultation data for climate monitoring: intercomparison of CHAMP refractivity climate records from 2002 to 2006 from different data centers, J. Geophys. Res., 114, D23107, doi:10.1029/2009JD011969, 2009.

Horwath, J. and Perlot, N.: Atmospheric impacts on ILO signals: Scintillation, Tech. Rep. for ESA-ESTEC Technical Note 4 Part of the TR-IRPERF Report, Deutsches Zentrum für Luft- und Raumfahrt, Oberpfaffenhofen, Germany, 2008.

$\mathrm{Hu}$, Y. X. and Stamnes, K.: An accurate parameterization of the radiative properties of water clouds suitable for use in climate models, J. Climatol., 6, 728-742, doi:10.1175/15200442(1993)006<0728:AAPOTR > 2.0.CO;2, 1993.

Key, J. R., Yang, P., Baum, B. A., and Nasiri, S. L.: Parameterization of shortwave ice cloud optical properties for various particle habits, J. Geophys. Res., 107, 4181, doi:10.1029/2001JD000742, 2002.

Kirchengast, G.: Occultations for probing atmosphere and climate: Setting the scene, in: Occultations for Probing Atmosphere and Climate, edited by: Kirchengast, G., Foelsche, U., and Steiner, A. K., Springer, Berlin, Heidelberg, Germany, 1-8, 2004.

Kirchengast, G. and Høeg, P.: The ACE+ mission: An Atmosphere and Climate Explorer based on GPS, GALILEO, and LEO-LEO radio occultation, in: Occultations for Probing Atmosphere and Climate, edited by: Kirchengast, G., Foelsche, U., and Steiner, A. K., Springer, Berlin, Heidelberg, Germany, 201-220, 2004.

Kirchengast, G. and Schweitzer, S.: ACCURATE LEO-LEO infrared laser occultation initial assessment: Requirements, payload characteristics, scientific performance analysis, and breadboarding specifications, Tech. Rep. for FFG-ALR No. 3/2007, Wegener Center, Univ. of Graz, Graz, Austria, 2007.

Kirchengast, G. and Schweitzer, S.: Climate benchmark profiling of greenhouse gases and thermodynamic structure and wind from space, Geophys. Res. Lett., 38, L13701, doi:10.1029/2011GL047617, 2011.

Kirchengast, G., Bernath, P. F., Buehler, S., Durry, G., Facheris, L., Gerbig, C., Haimberger, L., Harris, J., Hauchecorne, A., Kyrölä, E., Larsen, G. B., Sausen, R., Anthes, R. A., Gorbunov, M. E., Kursinski, E. R., Leroy, S. S., Trenberth, K., Randel, B., Gille, J., and Tsuda, T.: ACCURATE - climate benchmark profiling of greenhouse gases and thermodynamic variables and wind from space (ESA Earth Explorer Opportunity Mission EE-8 proposal), Sci. Rep. No. 36-2010, available at: http: //www.wegcenter.at/wcv, (last access: 19 August 2011), document wcv-scirep-no36-gkirchengastetal-jul2010.pdf, Wegener Center Verlag, Graz, Austria, 2010.

Kursinski, E. R., Hajj, G. A., Schofield, J. T., Linfield, R. P., and Hardy, K. R.: Observing Earth's atmosphere with radio occultation measurements using the Global Positioning System, J. Geophys. Res., 102, 23429-23465, doi:10.1029/97JD01569, 1997.

Kursinski, E. R., Hajj, G. A., Leroy, S. S., and Herman, B.: The GPS radio occultation technique, Terr. Atmos. Ocean. Sci., 11, 53-114, 2000.

Kursinski, E. R., Syndergaard, S., Flittner, D., Feng, D., Hajj, G. A., Herman, B., Ward, D., and Yunck, T.: A 
microwave occultation observing system to characterize atmospheric water, temperature, and geopotential via absorption, J. Atmos. Ocean. Tech., 19, 1897-1914, doi:10.1175/15200426(2002)019<1897:AMOOSO>2.0.CO;2, 2002.

Kursinski, E. R., Feng, D., Flittner, D., Hajj, G., Herman, B., Romberg, F., Syndergaard, S., Ward, D., and Yunck, T.: An active microwave limb sounder for profiling water vapour, ozone, temperature, geopotential, clouds, isotopes and stratospheric winds, in: Occultations for Probing Atmosphere and Climate, edited by: Kirchengast, G., Foelsche, U., and Steiner, A. K., Springer, Berlin, Heidelberg, Germany, 173-187, 2004.

Kursinski, E. R., Ward, D., Otarola, A., Frehlich, R., Groppi, C., Albanna, S., Shein, M., Bertiger, W., Pickett, H., and Ross, M.: The Active Temperature Ozone and Moisture Microwave Spectrometer (ATOMMS), in: New Horizons in Occultation Research: Studies in Atmosphere and Climate, edited by: Steiner, A. K., Pirscher, B., Foelsche, U., and Kirchengast, G., Springer, Berlin, Heidelberg, Germany, 295-313, 2009.

Kyrölä, E., Tamminen, J., Leppelmeier, G. W., Sofieva, V., Hassinen, S., Bertaux, J. L., Hauchecorne, A., Dalaudier, F., Cot, C., Korablev, O., d'Andon, O. F., Barrot, G., Mangin, A., Théodore, B., Guirlet, M., Etanchaud, F., Snoeij, P., Koopman, R., Saavedra, L., Fraisse, R., Fussen, D., and Vanhellemon, F.: GOMOS on Envisat: an overview, Adv. Space Res., 33, 1020-1028, doi:10.1016/S0273-1177(03)00590-8, 2004.

Landolt-Börnstein: Geophysics of the Solid Earth, the Moon and the Planets - Numerical Data and Functional Relationships, in: Science and Technology, edited by: Fuchs, K. and Stoffel, H., vol. V/2a, Springer, Berlin, Heidelberg, 332-336, 1984.

Li, F., Austin, J., and Wilson, J.: The strength of the Brewer-Dobson circulation in a changing climate: coupled chemistry-climate model simulations, J. Climatol., 21, 40-57, doi:10.1175/2007JCLI1663.1, 2008.

Liou, K. N.: An Introduction to Atmospheric Radiation, Academic Press, 2nd Edn., San Diego, California, USA, 2002.

Phinney, R. A. and Anderson, D. L.: On the radio occultation method for studying planetary atmospheres, J. Geophys. Res., 73, 1819-1827, doi:10.1029/JA073i005p01819, 1968.

Proschek, V., Kirchengast, G., and Schweitzer, S.: Greenhouse gas profiling by infrared-laser and microwave occultation: retrieval algorithm and demonstration results from end-to-end simulations, Atmos. Meas. Tech., 4, 2035-2058, doi:10.5194/amt-42035-2011, 2011a.

Proschek, V., Schweitzer, S., and Kirchengast, G.: Greenhouse gas profiles retrieval from IR-laser occultation data in cloudy air, Tech. Rep. for FFG-ALR No. 1/2011, Wegener Center, Univ. of Graz, Graz, Austria, 2011b.

Rothman, L. S., Jacquemart, D., Barbe, A., Benner, D. C., Birk, M., Brown, L. R., Carleer, M. R., Chackerian Jr., C., Chance, K., Coudert, L. H., Dana, V., Devi, V. M., Flaud, J.-M., Gamache, R. R., Goldman, A., Hartmann, J.-M., Jucks, K. W., Maki, A. G., Mandin, J.-Y., Massie, S. T., Orphal, J., Perrin, A., Rinsland, C. P., Smith, M. A. H., Tennyson, J., Tolchenov, R. N., Toth, R. A., Vander Auwera, J., Varanasi, P., and Wagner, G.: The HITRAN 2004 molecular spectroscopic database, J. Quant. Spectrosc. Ra., 96, 139-204, doi:10.1016/j.jqsrt.2004.10.008, 2005.

Rothman, L. S., Gordon, I. E., Barbe, A., Benner, D. C., Bernath, P. F., Birk, M., Boudon, V., Brown, L. R., Campargue, A., Champion, J.-P., Chance, K., Coudert, L. H., Dana, V., Devi,
V. M., Fally, S., Flaud, J.-M., Gamache, R. R., Goldman, A., Jacquemart, D., Kleiner, I., Lacome, N., Lafferty, W. J., Mandin, J.-Y., Massie, S. T., Mikhailenko, S. N., Miller, C. E., Moazzen-Ahmadi, N., Naumenko, O. V., Nikitin, A. V., Orphal, J., Perevalov, V. I., Perrin, A., Predoi-Cross, A., Rinsland, C. P., Rotger, M., Šimečková, M., Smith, M. A. H., Sung, K., Tashkun, S. A., Tennyson, J., Toth, R. A., Vandaele, A. C., and Vander Auwera, J.: The HITRAN 2008 molecular spectroscopic database, J. Quant. Spectrosc. Ra., 110, 533-572, doi:10.1016/j.jqsrt.2009.02.013, 2009.

Salby, M. L.: Fundamentals of Atmospheric Physics, Academic Press, San Diego, California, USA, 1996.

Schweitzer, S.: The ACCURATE concept and the infrared laser occultation technique: Mission design and assessment of retrieval performance (Ph.D. thesis), Sci. Rep. No. 34-2010, available at: http://www.wegcenter.at/wcv, (last access: 19 August 2011), document wcv-scirep-no34-sschweitzer-jun2010.pdf, Wegener Center Verlag, Graz, Austria, 2010.

Schweitzer, S., Kirchengast, G., and Ladstädter, F.: Enhancement of the end-to-end occultation simulation tool EGOPS for enabling quasi-realistic simulations of LEO-LEO IR laser occultation measurements, Tech. Rep. for FFG-ALR No. 1/2007, Wegener Center, Univ. of Graz, Graz, Austria, 2007.

Schweitzer, S., Pirscher, B., Pock, M., Ladstädter, F., Borsche, M., Foelsche, U., Fritzer, J. M., and Kirchengast, G.: End-toend Generic Occultation Performance Simulation and Processing System EGOPS: Enhancement of GPS RO data processing and IR laser occultation capabilities, Tech. Rep. for FFGALR No. 1/2008, Wegener Center, Univ. of Graz, Graz, Austria, 2008.

Schweitzer, S., Kirchengast, G., Schwärz, M., Fritzer, J. M., and Gorbunov, M. E.: Thermodynamic state retrieval from microwave occultation data and performance analysis based on end-to-end simulations, J. Geophys. Res., 116, D10301, doi:10.1029/2010JD014850, 2011.

Sofieva, V.: Atmospheric impacts on ILO signals: Assessment of infrared scintillations, Tech. Rep. for ESA-ESTEC Technical Note 3 - Part of the TR-IRPERF Report, Finnish Meteorological Institute, Helsinki, Finland, 2009.

Steiner, A. K., Kirchengast, G., Foelsche, U., Kornblueh, L., Manzini, E., and Bengtsson, L.: GNSS occultation sounding for climate monitoring, Phys. Chem. Earth, 26, 113-124, doi:10.1016/S1464-1895(01)00034-5, 2001.

Steiner, A. K., Kirchengast, G., Lackner, B. C., Pirscher, B., Borsche, M., and Foelsche, U.: Atmospheric temperature change detection with GPS radio occultation 1995 to 2008, Geophys. Res. Lett., 36, L18702, doi:10.1029/2009GL039777, 2009.

Syndergaard, S.: Retrieval analysis and methodologies in atmospheric limb sounding using the GNSS radio occultation technique, PhD-Thesis, Sci. Rpt. 99-6, Danish Metorol. Inst., Copenhagen, 1999.

Thomason, L. and Peter, T.: Assessment of stratospheric aerosol properties, WMO, Sparc Scientific Steering Group, Toronto, Canada, 322 pp., 2006.

Thomason, L. W. and Taha, G.: SAGE III aerosol extinction measurements: Initial results, Geophys. Res. Lett., 30, 1631, doi:10.1029/2003GL017317, 2003. 